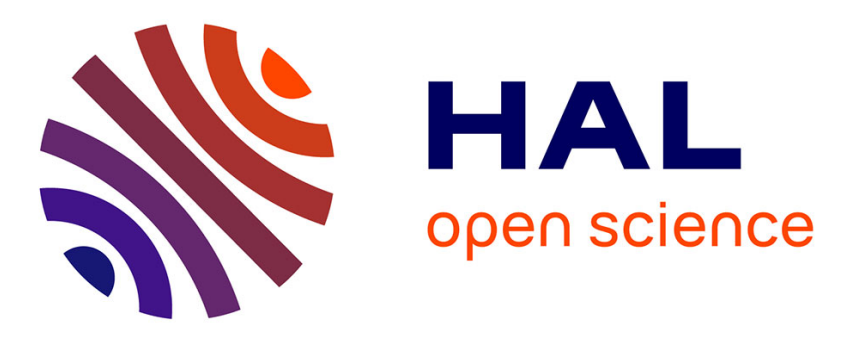

\title{
Rationalizability and Efficiency in an Asymmetric Cournot Oligopoly
}

Gabriel Desgranges, Stéphane Gauthier

\section{To cite this version:}

Gabriel Desgranges, Stéphane Gauthier. Rationalizability and Efficiency in an Asymmetric Cournot Oligopoly. 2015. halshs-00975002v3

\section{HAL Id: halshs-00975002 \\ https://shs.hal.science/halshs-00975002v3}

Submitted on 11 Dec 2015

HAL is a multi-disciplinary open access archive for the deposit and dissemination of scientific research documents, whether they are published or not. The documents may come from teaching and research institutions in France or abroad, or from public or private research centers.
L'archive ouverte pluridisciplinaire HAL, est destinée au dépôt et à la diffusion de documents scientifiques de niveau recherche, publiés ou non, émanant des établissements d'enseignement et de recherche français ou étrangers, des laboratoires publics ou privés. 


\section{Documents de Travail du PANTHEON SORBONNE Centre d'Economie de la Sorbonne}
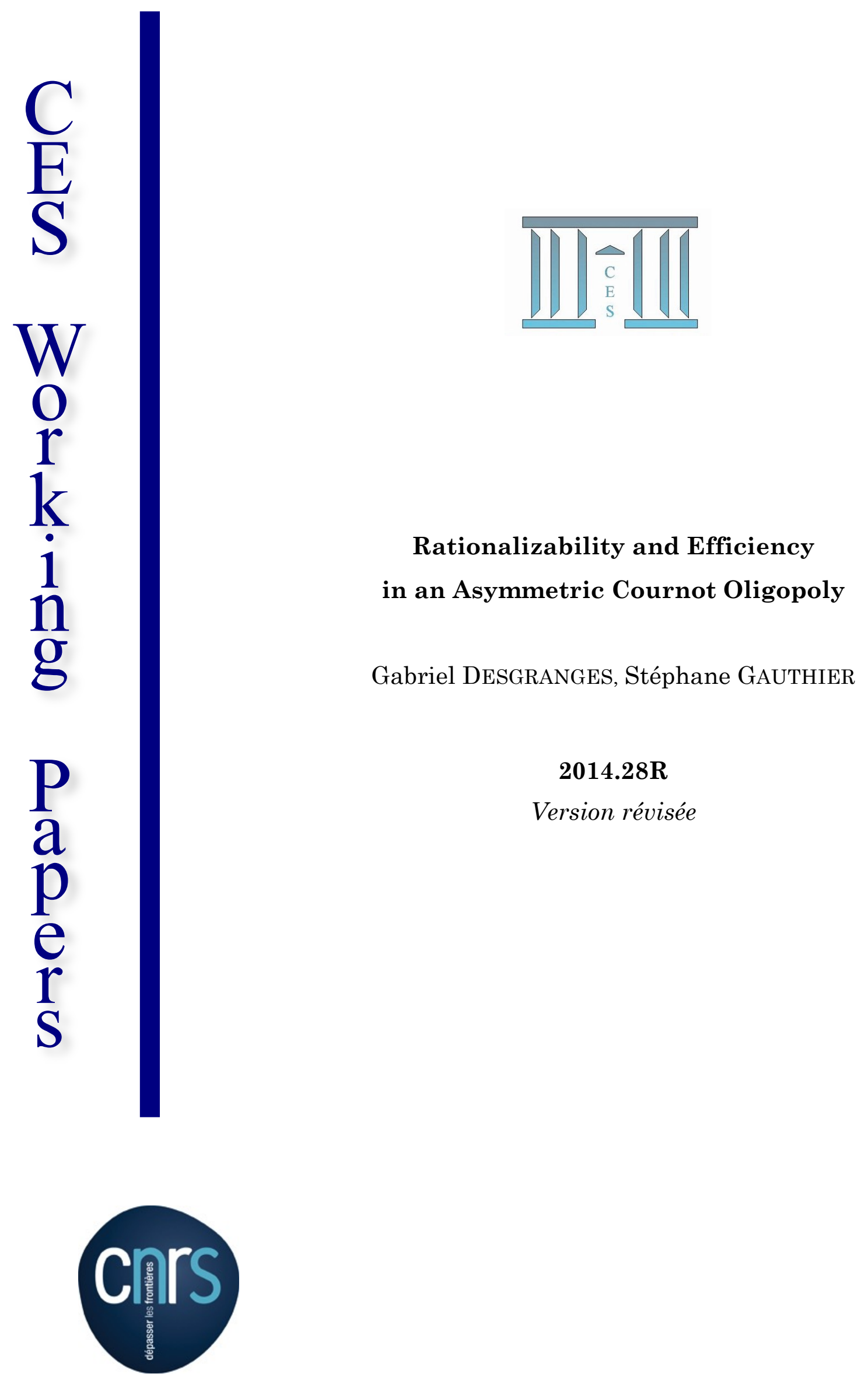

Maison des Sciences Économiques, 106-112 boulevard de L'Hôpital, 75647 Paris Cedex 13 http://centredeconomiesorbonne.univ-paris1.fr/ 


\title{
Rationalizability and Efficiency in an Asymmetric Cournot Oligopoly* \\ Gabriel Desgranges ${ }^{\dagger}$ and Stéphane Gauthier
}

October 27, 2015

\begin{abstract}
This paper studies rationalizability in a linear asymmetric Cournot oligopoly with a unique Nash equilibrium. It shows that mergers favors uniqueness of the rationalizable outcome. When one requires uniqueness of the rationalizable outcome maximization of consumers' surplus may involve a symmetric oligopoly with few firms. We interpret uniqueness of the rationalizable outcome as favoring a dampening of strategic 'coordination' uncertainty. An illustration to the merger between Delta Air Lines and Northwest shows that a reallocation of $1 \%$ of market share from a small carrier to a larger one has implied a lower production volatility over time, yielding a $1.5 \%$ decrease in the coefficient of variation of number of passengers.
\end{abstract}

JEL codes: D43, D84, L40.

Keywords: competition policy, Cournot oligopoly, dominance solvability, efficiency, rationalizability, stability, airline industry.

*We thank Jess Benhabib, Gaetano Gaballo, Roger Guesnerie, Laurent Linnemer, Régis Renault, JeanPhilippe Tropéano and Thibault Vergé for useful discussions. Alexandra Belova, Philippe Gagnepain, Nicolas Jacquemet, Benoît Rapoport and especially Antoine Terracol provided us generous guidance in the empirical illustration to the airline industry. We are very grateful to two anonymous referees and the editor Pierre Dubois for helping us to improve our paper. The usual disclaimers apply.

${ }^{\dagger}$ University of Cergy-Pontoise, gabriel.desgranges@u-cergy.fr

${ }^{\ddagger}$ Paris School of Economics and University of Paris 1, stephane.gauthier@univ-paris1.fr 


\section{Introduction}

In a Cournot-Nash equilibrium, every firm is assumed to predict correctly the behavior of its competitors. Rationalizability criteria are much less demanding. The set of rationalizable outcomes comprises any outcome that can occur when firms expect some outcome in this set. This set therefore includes Cournot-Nash equilibria but it is often larger. It may for instance include production levels around the equilibrium: a firm expecting the others to produce above the equilibrium, and so expecting a price lower than the equilibrium price to arise, will produce below equilibrium.

The aim of this paper is to relate rationalizability to the market structure in a Cournot oligopoly. The market structure is characterized by an exogenous distribution of productive assets across firms, as in Perry and Porter (1985). This kind of setups naturally arises in competition policy when a regulator has to choose how to allocate some production capacity across different competitors. This applies to nuclear reactors in the power industry (Davis and Wolfram, 2011), hospitals in the health insurance market (Town et al., 2006) or water sources (Compte et al., 2002). The regulator usually tries to reach equal sharing of capacity across a large number of firms. The standard justification for this policy is that consumers' surplus is lower in the equilibrium corresponding to a monopoly-like situation, with one firm holding most of the productive assets, than in a competitive equilibrium where each of a large number of competitors retains control over similar capacity.

The rationalizability viewpoint leads to qualify this recommendation. The general flavor of our results is that an asset reallocation improving consumers' surplus in the equilibrium may in fact give rise to a multiplicity of rationalizable outcomes, making less likely that the equilibrium be ever achieved. In order to grasp intuition consider two firms that differ according to production capacity. Equal sharing supposes to reallocate some assets from the large to the small firm. Such a reallocation relaxes the capacity constraint of the small firm, making its production less predictable. In turn the behavior of the large firm, reacting to its expectation about the production of the small firm, also becomes less predictable.

We give a formal account of this intuition by appealing to rationalizability. The set of rationalizable outcomes is computed using an iterated process of elimination of strategies that are non best responses. At the beginning of the process, no restriction is made about beliefs. The first step eliminates the decisions that are not rational, i.e., not best response to some belief. The second step then eliminates all the decisions that are not best responses to beliefs in the set of rational decisions. Every further step eliminates the decisions that are not best responses to beliefs about decisions surviving the previous steps. This process eventually yields the set of rationalizable outcomes. There is a unique rationalizable outcome when the process is contracting, i.e., it is governed by a mapping with spectral radius less than one (Bernheim, 1984; Moulin, 1984).

We provide a global characterization of the set of rationalizable outcomes in a linear asymmetric Cournot setup with a unique Nash equilibrium. Our main result shows that the spectral radius of the mapping governing iterated elimination of non best responses increases following a reallocation of assets from a large firm to a smaller one. Achieving 
a higher consumers' surplus in the equilibrium may consequently be associated with a multiplicity of rationalizable outcomes. In addition we show that in case of multiplicity such a reallocation enlarges the set of rationalizable aggregate productions.

Once Nash assumptions are relaxed, looking for a consumers' surplus improvement makes questionable policies involving unrestrained pursuit of competition. We characterize the asset distribution maximizing the aggregate equilibrium production subject to the constraint that the equilibrium is the only rationalizable outcome. When the competitive equilibrium is the only rationalizable outcome, this is indeed the solution we look for. Otherwise, the solution is an oligopoly with few identical firms. We finally show that this same asset distribution maximizes the lowest rationalizable aggregate production. In this sense, a regulator who displays high risk aversion and so puts high probability of occurrence on worst rationalizable productions should not implement an asset distribution implying multiple rationalizable outcomes.

Bernheim (1984), Basu (1992) and Börgers and Janssen (1995) study rationalizability in symmetric Cournot games. Guesnerie (1992) studies eductive stability (that coincides with uniqueness of rationalizable outcomes) in the competitive case, and Gaballo (2013) considers eductive stability in linear symmetric Cournot games. The closest paper to ours is Moulin (1984). Moulin (1984) provides a condition for local Cournot (cobweb) stability and shows that this condition locally governs elimination of non best responses. Rationalizability can also be analyzed exploiting the supermodular game structure of Cournot duopolies or symmetric oligopolies (Vives 1990; Amir 1996) but this approach does not extend to more general frameworks (Vives, 1999).

The process of iterated elimination allows for an interpretation of rationalizability as the consequence of introspection. Other criteria for Nash robustness include real time learning where agents revise their beliefs from observations of past outcomes. See, among others, Milgrom and Roberts (1990), Guesnerie (1993), Marx (1999), Hommes and Wagener (2010) or Durieu, Solal and Tercieux (2011). The Rationalizable Conjectural Equilibrium introduced by Rubinstein and Wolinsky (1994) and Esponda (2013) involves both introspection and feedback from observations. The literature suggests the existence of close links between all these approaches.

The empirical literature provides no clear evidence that concentration is associated with higher prices (Gugler et al., 2003). This is often viewed as reflecting a trade-off between economies of scale and the ability of larger firms to exercise market power (Williamson, 1968; Perry and Porter, 1985; Farrell and Shapiro, 1990). Our theoretical model focuses on one aspect of a merger: a merger is one form of reallocation of productive assets. Focusing on this aspect our results suggest that changes in the set of rationalizable outcomes caused by mergers may also blur the impact on the price level. In the airlines industry there is mixed evidence that fare dispersion is higher in competitive routes (Borenstein and Rose, 1994; Gerardi and Shapiro, 2009). Our paper considers quantity instead of price dispersion. We provide empirical evidence consistent with the theory that in the airlines industry the main recent mergers have led to reduced intra-route passenger volatility. In the specific case of the merger between Delta Air Lines and Northwest we find that a 1 percent transfer 
of market share from a small firm to a larger one decreases within carriers coefficient of variation of the number of passengers by 1.5 percent.

The paper is organized as follows. In Section 2 we briefly present the setup and we show that equilibrium production increases following a reallocation of assets from a large firm to a smaller one. In Section 3 we give a necessary and sufficient condition for the equilibrium to be the only rationalizable outcome. In Section 4 we establish the trade-off between efficiency in equilibrium and uniqueness of the rationalizable outcome. In Section 5 we characterize the optimal distribution of assets. The illustration to the airline industry is given in Section 6 .

\section{General setup}

We consider a single product model of Cournot competition with $M$ firms and $N$ identical productive assets. Firm $\ell$ owns $N_{\ell}$ assets, with $N_{\ell}$ decreasing in $\ell\left(N_{\ell} \in \mathbb{R}_{+}\right)$. Producing $q_{\ell} \operatorname{costs} C\left(q_{\ell}, N_{\ell}\right)=q_{\ell}^{2} / 2 \sigma N_{\ell}$ to firm $\ell(\sigma>0)$. One can think of an asset as a plant, and assume that producing $q$ goods from a plant costs $q^{2} / 2 \sigma$. By convexity, a firm minimizes its overall cost by producing the same quantity $q$ in each plant, yielding total cost $C\left(q N_{\ell}, N_{\ell}\right)$.

Given $N_{\ell}$ firm $\ell$ produces $q_{\ell}$ maximizing $p\left(q_{\ell}+Q_{-\ell}\right) q_{\ell}-C\left(q_{\ell}, N_{\ell}\right)$, where $Q_{-\ell}$ is the aggregate production of firms other than $\ell$ and $p(\cdot)=\delta_{0}-\delta Q$ is the inverse demand function (where $Q$ is the aggregate production, and $\delta, \delta_{0}>0$ ). Its best response is

$$
R_{\ell}\left(Q_{-\ell}\right)=\left\{\begin{array}{cl}
q_{\ell}^{m}-b_{\ell} Q_{-\ell} & \text { if } Q_{-\ell} \leq \delta_{0} / \delta \\
0 & \text { if } Q_{-\ell} \geq \delta_{0} / \delta
\end{array}\right.
$$

where $q_{\ell}^{m}=b_{\ell} \delta_{0} / \delta$ is the monopoly production of firm $\ell$, and

$$
b_{\ell}=\frac{\sigma \delta N_{\ell}}{2 \delta \sigma N_{\ell}+1} \geq 0 .
$$

With this specification the slope $b_{\ell}$ of the reaction function is increasing and concave in $N_{\ell}$.

A Cournot equilibrium is a $M$-vector $\left(q_{\ell}^{*}\right)$ such that $q_{\ell}^{*}=R_{\ell}\left(Q_{-\ell}^{*}\right)$ for every $\ell$. There is a unique equilibrium. In this equilibrium, productions are

$$
\left(\begin{array}{c}
q_{1}^{*} \\
\vdots \\
q_{M}^{*}
\end{array}\right)=(I+B)^{-1}\left(\begin{array}{c}
q_{1}^{m} \\
\vdots \\
q_{M}^{m}
\end{array}\right)
$$

where $I$ is the identity matrix of order $M$ and $B$ is the square positive matrix

$$
B=\left(\begin{array}{cccc}
0 & b_{1} & \cdots & b_{1} \\
b_{2} & \ddots & & \vdots \\
\vdots & & \ddots & b_{M-1} \\
b_{M} & \cdots & b_{M} & 0
\end{array}\right)
$$


Let $Q^{*}$ be the aggregate production in the equilibrium. Since the price $p\left(Q^{*}\right)$ is positive (otherwise no firm would be active in equilibrium) and the marginal cost tends to zero when production tends to zero, it is always profitable for a firm to enter the market. Hence all the firms are active in equilibrium ( $q_{\ell}^{*}>0$ for every $\ell$ ).

Our first result states that an equal distribution of assets across firms yields the highest aggregate production in equilibrium, and thus the highest consumers' surplus.

Proposition 1. A transfer of assets from firm $h$ to firm $s$ increases the aggregate output $Q^{*}$ in the Cournot equilibrium if and only if $N_{h}>N_{s}$ (firm $h$ is larger than firm s).

Proof. The equilibrium aggregate production is

$$
Q^{*}=\frac{S}{1+S} \frac{\delta_{0}}{\delta}, \quad \text { with } S=\sum_{\ell=1}^{M} \frac{b_{\ell}}{1-b_{\ell}} .
$$

The production $Q^{*}$ increases in $S$, and the ratio $b_{\ell} /\left(1-b_{\ell}\right)$ is increasing and concave in $N_{\ell}$. A transfer of assets from a large to a small firm implies a lower $b_{h} /\left(1-b_{h}\right)$ and a higher $b_{s} /\left(1-b_{s}\right)$. By concavity, $S$ increases, and so $Q^{*}$ increases.

This result is a particular case of Perry and Porter (1985) or Farrell and Shapiro (1990). It includes the case of a merger (a merger between firms $s$ and $h$ amounts to transfer all the assets of $s$ to $h$ ). A corollary of Proposition 1 is that, when all the firms have the same number of assets, $Q^{*}$ increases with the number $M$ of firms (from a symmetric oligopoly with $M$ firms, the transfer of all the assets of one firm to the others results into a symmetric oligopoly with $M-1$ firms). Hence, given $N$, the production $Q^{*}$ and the consumers' surplus are maximized in a competitive equilibrium (an equilibrium with an infinite number of identical firms).

\section{Dominance solvability}

An equilibrium is dominant solvable when it is the unique rationalizable outcome of the Cournot game.

Rationalizable outcomes are defined from the following process. Suppose that every firm $\ell$ produces in $\left[q_{\ell}^{\inf }(0), q_{\ell}^{\text {sup }}(0)\right)=[0,+\infty)$. Then, define iteratively (for all $t \geq 1$ ) the sequences $\left[q_{\ell}^{\inf }(t), q_{\ell}^{\text {sup }}(t)\right]$ of sets of best responses of firm $\ell$ to the belief that the aggregate production of others is in $\left[Q_{-\ell}^{\inf }(t-1), Q_{-\ell}^{\text {sup }}(t-1)\right]$, with $Q_{-\ell}^{\inf }(t-1)=\sum_{k \neq \ell} q_{k}^{\inf }(t-1)$ and $Q_{-\ell}^{\text {sup }}(t-1)=\sum_{k \neq \ell} q_{k}^{\text {sup }}(t-1)$. Strategic substitutabilities imply that

$$
q_{\ell}^{\inf }(t)=R_{\ell}\left(Q_{-\ell}^{\text {sup }}(t-1)\right), \quad \text { and } q_{\ell}^{\text {sup }}(t)=R_{\ell}\left(Q_{-\ell}^{\inf }(t-1)\right) .
$$

For all $\ell$ the sequences are converging since $\left(q_{\ell}^{\inf }(t)\right)$ increases in $t,\left(q_{\ell}^{\text {sup }}(t)\right)$ decreases in $t$, and they are bounded $\left(0 \leq q_{\ell}^{\inf }(t) \leq q_{\ell}^{*} \leq q_{\ell}^{\text {sup }}(t) \leq q_{\ell}^{m}\right.$ for all $\left.t \geq 1\right)$. Their limits, denoted 
$q_{\ell}^{\mathrm{inf}}$ and $q_{\ell}^{\text {sup }}$, are fixed points of the recursive system (4). The limit set $\left[q_{\ell}^{\mathrm{inf}}, q_{\ell}^{\text {sup }}\right]$ is the set of rationalizable productions of firm $\ell$.

Local dominance solvability is defined as the uniqueness of the rationalizable outcome in a game where the strategy sets are restricted to a neighborhood of the equilibrium $\left(q_{\ell}^{\inf }(0)\right.$ and $q_{\ell}^{\text {sup }}(0)$ are close to $q_{\ell}^{*}$ for every firm). Under this restriction, all the firms are active, and the recursive system (4) becomes

$$
\left(\begin{array}{c}
q_{1}^{\inf }(t) \\
\vdots \\
q_{M}^{\inf }(t)
\end{array}\right)=\left(\begin{array}{c}
q_{1}^{m} \\
\vdots \\
q_{M}^{m}
\end{array}\right)-B\left(\begin{array}{c}
q_{1}^{\text {sup }}(t-1) \\
\vdots \\
q_{M}^{\text {sup }}(t-1)
\end{array}\right)
$$

and

$$
\left(\begin{array}{c}
q_{1}^{\text {sup }}(t) \\
\vdots \\
q_{M}^{\text {sup }}(t)
\end{array}\right)=\left(\begin{array}{c}
q_{1}^{m} \\
\vdots \\
q_{M}^{m}
\end{array}\right)-B\left(\begin{array}{c}
q_{1}^{\inf }(t-1) \\
\vdots \\
q_{M}^{\inf }(t-1)
\end{array}\right)
$$

Local dominance solvability obtains when this system is contracting, i.e., the spectral radius of $B$ is less than 1 .

Lemma 1. The spectral radius of $B$ is the unique positive root $\rho$ of

$$
F(\rho) \equiv \sum_{\ell=1}^{M} \frac{b_{\ell}}{\rho+b_{\ell}}=1 .
$$

We have $\rho<1 \Leftrightarrow F(1)<1$.

Proof. Let $e$ be an eigenvalue of $B$, and $v$ an associated eigenvector. Then, $e v=B v$ yields

$$
e v_{\ell}+b_{\ell} v_{\ell}=b_{\ell} \sum_{k=1}^{M} v_{k} \Leftrightarrow v_{\ell}=\frac{b_{\ell}}{e+b_{\ell}} \sum_{k=1}^{M} v_{k} \quad \text { for all } \ell .
$$

Summing over $\ell$ implies that every eigenvalue $e$ of $B$ is such that

$$
F(e) \equiv \sum_{\ell=1}^{M} \frac{b_{\ell}}{e+b_{\ell}}=1 .
$$

For $e \geq 0$, the function $F$ is continuous and decreasing. Moreover, $F(0)=n>1>0=$ $F(+\infty)$. Hence, $B$ admits a unique positive real eigenvalue. Since $B$ is a positive matrix, it follows from Perron-Frobenius theorem that this positive real eigenvalue is the spectral radius $\rho$ of $B$. That is, $F(\rho)=1$ for $\rho>0$. Finally, since $F$ is decreasing, we have: $\rho<1$ if and only if $F(1)<1$.

The inequality $F(1)<1$ is the local condition found by Moulin (1984). We are going to show that this is also the condition for global dominance solvability of the equilibrium. 
This is done by investigating the set of rationalizable outcomes. With identical firms, either the equilibrium is dominant solvable $\left(q_{\ell}^{\text {inf }}=q_{\ell}^{\text {sup }}=q_{\ell}^{*} \equiv q^{*}\right.$ for all $\ell$ ), or $\left[q_{\ell}^{\text {inf }}, q_{\ell}^{\text {sup }}\right]=\left[0, q^{m}\right]$ with $q^{m}=q_{\ell}^{m}$ for all $\ell$ (see, e.g., Basu, 1992). In our setup firms are heterogeneous and it is no longer true that $q_{\ell}^{\text {inf }}=0$ for every $\ell$ when the equilibrium is not dominant solvable. The next result shows that the values of $q_{\ell}^{\text {inf }}$ are ranked according to $\ell$.

Lemma 2. The bounds $q_{\ell}^{\text {inf }}$ and $q_{\ell}^{\text {sup }}$ are nonincreasing in $\ell$. Furthermore, the lowest rationalizable production $q_{\ell}^{\mathrm{inf}}$ is 0 if and only if $\ell>\bar{\ell}$, where $\bar{\ell} \geq 0$ is the largest $\ell$ such that

$$
\sum_{k \leq \ell} \frac{b_{k}}{1+b_{k}}+\sum_{k>\ell} \frac{b_{k}}{1+b_{\ell}}<1
$$

Proof. See in appendix.

To get an intuition about the existence of the threshold $\bar{\ell}$, let us consider the first two steps of the iterative process of elimination of non best responses. In the first step, $q_{\ell}^{\text {sup }}(1)$ is the monopoly production $q_{\ell}^{m}$ which is decreasing in $\ell$ (it is increasing in the number of assets). In the second step, $q_{\ell}^{\text {inf }}(2)$ is the best response to $Q_{-\ell}^{\text {sup }}(1)$ which is increasing in $\ell$ (small firms face a higher aggregate production of others than large firms). It follows that $q_{\ell}^{\text {inf }}(2)$ is decreasing in $\ell$ and possibly 0 for $\ell$ large enough. The argument extends to every further step of the elimination process.

Given the threshold $\bar{\ell}$, we can characterize the rationalizable outcomes of a linear Cournot game.

Lemma 3. The set of rationalizable aggregate productions is the interval $\left[Q^{\mathrm{inf}}, Q^{\mathrm{sup}}\right]$, where

$$
Q^{\mathrm{inf}}=\left(1+\frac{c-a}{a^{2}-c(c+e)}\right) \frac{\delta_{0}}{\delta}, \quad Q^{\mathrm{sup}}=Q^{\mathrm{inf}}+\frac{e}{a^{2}-c(c+e)} \frac{\delta_{0}}{\delta}
$$

with

$$
a=1+\sum_{\ell \leq \bar{\ell}} \frac{b_{\ell}^{2}}{1-b_{\ell}^{2}}, c=\sum_{\ell \leq \bar{\ell}} \frac{b_{\ell}}{1-b_{\ell}^{2}} \text { and } e=\sum_{\ell>\bar{\ell}} b_{\ell} .
$$

Proof. See in appendix. The appendix also characterizes the set $\left[q_{\ell}^{\mathrm{inf}}, q_{\ell}^{\mathrm{sup}}\right]$ of rationalizable individual productions.

Lemma 2 directly yields a necessary and sufficient condition for dominance solvability of the Cournot game. On the one hand, when all the firms are active $(\bar{\ell}=M), q_{\ell}^{\text {inf }}=q_{\ell}^{\text {sup }}=q_{\ell}^{*}$ for all $\ell$ since the equilibrium is the unique fixed point of the linear system (4). On the other hand, the Cournot equilibrium is not the only rationalizable outcome when some firms remain inactive $(\bar{\ell}<M)$.

Proposition 2. The Cournot equilibrium is globally dominant solvable (the unique rationalizable outcome) if and only if $\bar{\ell}=M$, or equivalently

$$
\Gamma \equiv \sum_{\ell} \frac{b_{\ell}}{1+b_{\ell}}<1
$$


Proposition 2 generalizes the local analysis by taking into account the decision of entry analyzed in Lemma 2. It shows that (8) governs global dominance solvability, and thus rationalizability of entry.

For illustrative purpose, consider an example of non Nash rationalizable outcomes with identical firms, $b_{\ell}=b$ for all $\ell$. Condition (8) simplifies to $(M-1) b<1$. When the equilibrium is not dominant solvable, any rationalizable deviation from the equilibrium is justified by a belief in $\left[0, q^{m}\right]$. Firm $\ell$ can produce $q^{*}+\varepsilon$ when it expects everyone else to deviate by $-\varepsilon /[(M-1) b]$ from the equilibrium. This belief in turn is justified by second order beliefs: a firm believes that everyone produces below the equilibrium when it believes that everyone believes that everyone produces above the equilibrium (implying that everyone produces below the equilibrium). Higher order beliefs are defined in $\left[0, q^{m}\right]$ along the same lines.

\section{Rationalizability and asset distribution}

We now relate the asset distribution to the set of rationalizable outcomes. A first approach consists in studying how a change in the asset distribution affects the spectral radius $\rho$.

Proposition 3. A transfer of assets from firm $h$ to firm $s$ increases the spectral radius $\rho$ of $B$ if and only if firm $h$ is larger than firm $s\left(N_{h}>N_{s}\right)$.

Proof. Consider a transfer of $d N>0$ assets from firm $h$ to firm $s$, i.e., $N_{s}$ increases by $d N$ and $N_{h}$ decreases by $d N\left(N_{s}<N_{h}\right)$. The resulting change $d \rho$ in the spectral radius is obtained by differentiating (5):

$$
F^{\prime}(\rho) d \rho+\left[\frac{\partial}{\partial N_{s}}\left(\frac{b_{s}}{1+b_{s}}\right)-\frac{\partial}{\partial N_{h}}\left(\frac{b_{h}}{1+b_{h}}\right)\right] d N=0 .
$$

Since the ratio $b_{\ell} /\left(1+b_{\ell}\right)$ is increasing and concave in $N_{\ell}$, the term into brackets is positive. Since $F^{\prime}(\rho)<0$ for $\rho>0$, we have $d \rho>0$.

A transfer of assets from firm $h$ to firm $s$ implies a change in the slopes of their reaction functions. Since the (absolute value of the) slope is increasing in the number of assets, $b_{s}$ increases (which is detrimental to dominance solvability) and $b_{h}$ decreases (which favors dominance solvability). The overall effect follows from the concavity of the ratio $b_{\ell} /\left(1+b_{\ell}\right)$ in the number of assets. Proposition 3 shows that asymmetry across firms favors dominance solvability. In view of Propositions 1 any reallocation of assets which improves consumers' surplus in equilibrium makes less likely that this equilibrium be the unique rationalizable outcome. $^{1}$

\footnotetext{
${ }^{1}$ An alternative assessment could refer to $\Gamma$ characterized in Proposition 2. Proposition 3 holds true when $\rho$ is replaced by $\Gamma$.
} 
A second approach bears on the set of rationalizable aggregate productions $\left[Q^{\text {inf }}, Q^{\text {sup }}\right]$. The difference $Q^{\text {sup }}-Q^{\text {inf }}$ can be viewed as a measure of the strategic uncertainty in the market, a large interval $\left[Q^{\text {inf }}, Q^{\text {sup }}\right]$ magnifying strategic uncertainty. Our next result is another version of the trade-off between efficiency and dominance solvability: a reallocation of assets that yields higher aggregate production in equilibrium also raises $Q^{\text {sup }}-Q^{\text {inf }}$.

Proposition 4. Assume that the equilibrium is not dominant solvable $\left(Q^{\inf }<Q^{\text {sup }}\right)$. Consider an infinitesimal reallocation of assets from a large firm $h$ to a smaller one $s$, $d N_{h}=-d N_{s}<0\left(N_{s}<N_{h}\right)$. We have:

$$
d\left(Q^{\text {sup }}-Q^{\text {inf }}\right)>0 .
$$

Proof. See in appendix.

In order to grasp some intuition, consider again the iterative process (4). The production $q_{\ell}^{\text {sup }}(1)=q_{\ell}^{m}$ is increasing and concave in $N_{\ell}$. A reallocation of assets from firm $h$ to firm $s$ implies that $q_{h}^{m}$ decreases and $q_{s}^{m}$ increases. By concavity $q_{s}^{m}+q_{h}^{m}$ increases. Hence, for each firm $\ell \neq s$, the reallocation implies an increase in $Q_{-\ell}^{\text {sup }}(1)$ so that $q_{\ell}^{\text {inf }}(2)$ decreases. Firm $s$ faces a smaller production $Q_{-s}^{\text {sup }}(1)$ but this effect happens to be dominated by the aggregate effect on all the other firms. The argument then extends to every further step of the iterative process.

\section{Optimal asset distribution}

Consider a competition regulator who wants to implement an asset distribution maximizing aggregate production. In the presence of a multiplicity of rationalizable outcomes, the regulator cannot be certain about the actual aggregate production. A possible way to circumvent this problem is to restrict attention to asset distributions implying a unique rationalizable outcome. The asset distribution $\left(N_{\ell}\right)$ and the number $M$ of firms should then maximize the equilibrium aggregate production $Q^{*}$ defined by (3) subject to the dominant solvability constraint $F(1)<1$ in (8), and feasibility

$$
\sum_{\ell=1}^{M} N_{\ell} \leq N
$$

Proposition 5. Any $\left(\left(N_{\ell}\right), M\right)$ maximizing the aggregate equilibrium production $Q^{*}$ given by (3) subject to the constraints (8) and (9) involves an equal sharing of productive assets: $N_{\ell}=N / M$ for all $\ell$. Furthermore,

- if $\sigma \delta N<1$, then the solution involves an infinite number of firms (competitive market), and (9) is the only binding constraint; 
- if $\sigma \delta N \geq 1$, then the solution is a symmetric oligopoly with

$$
M^{* *}=\frac{3 \sigma \delta N}{\sigma \delta N-1}
$$

firms. ${ }^{2}$ The aggregate production is

$$
Q^{* *}=\frac{1}{2} \frac{3 \sigma \delta N}{1+2 \sigma \delta N} \frac{\delta_{0}}{\delta}
$$

Both constraints (8) and (9) are binding at the optimum.

Proof. See in appendix.

A competitive market structure obtains when the given (finite) capacity is equally shared among a arbitrarily large number of firms. The equilibrium in such a market is the only rationalizable outcome when $\sigma \delta N<1$. This is the condition found by Guesnerie (1992) with a continuum of total size $N=1$ of firms. By Proposition 5 perfect competition should be promoted when $\sigma \delta N<1$.

When $\sigma \delta N \geq 1$, there are multiple rationalizable outcomes in a competitive market. A first way to restore uniqueness is to allocate only a part of the assets. The equilibrium becomes dominant solvable when $1 / \sigma \delta$ assets $(1 / \sigma \delta<N)$ are allocated to a large number of firms. Perfect competition then involves production inefficiency with some productive assets being not used. A second way to restore uniqueness is to allocate all the assets to few firms only. The market structure now gets closer to a monopoly-like situation. Proposition 5 shows that this last alternative maximizes consumers' surplus.

Proposition 5 may provide biased insights into the optimal distribution of assets. Indeed, when $\sigma \delta N \geq 1$, there exist asset distributions where some rationalizable production is greater than $Q^{* *}$. Reaching such production levels could then justify the implementation of an asset distribution yielding a multiplicity of rationalizable outcomes. But this goal is met with certainty if and only if the asset distribution has $Q^{\text {inf }}$ greater than $Q^{* *}$. Our next result shows that this never happens.

Proposition 6. There is no distribution of assets such that the lowest aggregate production $Q^{\text {inf }}$ is greater than $Q^{* *}$.

Proof. See in appendix.

A competition regulator whose risk aversion toward the strategic uncertainty is infinite (the regulator puts a high probability on worst aggregate productions) should select an asset distribution implying dominance solvability of the equilibrium. Still high risk aversion does not always recommend to pick out the competitive outcome: the optimal asset distribution involves imperfect competition when the production capacity is large $(\sigma \delta N \geq 1)$.

\footnotetext{
${ }^{2}$ When $M^{* *}$ is not an integer, the solution is the largest integer below $M^{* *}$.
} 


\section{An Illustration from the U.S. Airline Industry}

Our theoretical analysis predicts that mergers could dampen market 'coordination' volatility by making more likely that firms form accurate beliefs about the behavior of their competitors. We assess this prediction by considering the case of the airline industry. In this industry a firm is an airline producing passenger transportation, a market is a route between two airports or cities, and available seats, aircraft fleet or some measure for airline network might provide plausible proxies for productive assets. The cost function appears like the structure assumed in the theoretical model when it is viewed as a smooth approximation of a situation where cost per passenger are low until the carrier reaches full capacity. The fixed costs that matter in the industry are however absent from the theoretical model.

\subsection{Data description}

Our data comes from the Airline Origin and Destination Survey (DB1B) collected by the US Department of Transportation. We use the number of coupons, the origin and destination countries and airports, the ticketing and operating carriers, and the number of passengers from the DB1B Market dataset. Each quarter about 4 to 6 million transactions are recorded in this dataset. We restrict our analysis to flights from 2000:Q1 to 2015:Q1, where the origin and the destination are within the boundaries of the US.

We delete observations with missing or coded 99 ticketing carrier as well as tickets with more than six coupons (Ciliberto and Tamer, 2009). We then aggregate the data so that an observation gives the number of passengers per (ticketing) carrier, route and quarter.

A route comprises all undirected flights between two airports, irrespective of intermediate transfer points. Following Borenstein (1990) we assume that flights involving two different airports in the same city are in separate markets. We exclude from the sample the routes where reported flights are in only one direction, and small routes where there is some quarter with no reported passengers. This gives us a sample of 2,937,091 observations comprising 16,058 routes.

\subsection{The merger between Delta and Northwest}

Most of the illustration is provided in the context of the merger between Delta Air Lines (DL) and Northwest Airlines (NW). The DL/NW merger started in 2008 over a period of high global volatility, with the Great Recession, soaring fuel prices and H1N1 flu pandemic. Early public information was released in January 2008 and the official announcement was made in April. The merger finally was approved by the Department of Justice in October 2008 and completed in January 2010.

We choose a pre-merger period running until the quarter 2007:Q4 (included) which

precedes the early announcement. Kim and Singal (1993) advocates for some specificity of the transitory period from the early announcement in 2008:Q1 to the completion in 2010:Q1. Since our theoretical analysis supposes that production facilities are actually 
transferred, we choose a post-merger period starting from the quarter 2010:Q2 that follows completion. In order to get rid from seasonal patterns we select pre and post-merger periods consisting of the same number of each quarter. As regional economies evolve routes may be subject to different long term trends. Therefore we also require that the two periods have the same length. The resulting pre-merger period thus runs from 2003:Q1 to 2007:Q4 and the post-merger period from 2010:Q2 to 2015:Q1. Each period covers 5 consecutive years and consists of 5 Q1 quarters, 5 Q2 quarters, etc.

Removing observations that are outside the time window and neglecting small carriers with less than $1 \%$ of market share per quarter we are left with a sample of $1,875,281$ observations.

\subsection{Control and treatment}

Following Kim and Singal (1993) we distinguish two groups of routes: those where both DL and NW are present before the early announcement, and those where they are never active. The routes in the first group are affected by the merger and they are used to build a treatment group. The routes in the last group are assumed to be not affected by the merger and form the basis for the control group.

There are 12,194 (resp., 9,740) routes where DL (resp. NW) is active (i.e., appears as ticketing carrier) during at least one quarter before the merger. The intersection of these two sets of routes yields 8,053 routes. We require strong presence of the two merging firms for including a route into the treatment group. First DL has to be active each quarter in the time window. This requirement selects 4,939 routes from the 8,053 routes. In this subset we choose the routes where NW is active each quarter before the merger. The treatment group finally comprises 412,943 observations, corresponding to the carriers present in 2,353 routes.

We apply the same criteria to the control group. We start from the 1,883 routes where both DL and NW are never active. We pay some attention to the possible indirect influence of DL and/or NW transiting through regional airlines bound by codeshare agreements. Almost all regional airlines are involved into codeshare agreements with at least one major carrier (Forbes and Lederman, 2009). Under codeshare regional airlines operate flights ticketed by major carriers. Since by construction neither DL nor NW tickets flights in these 1,883 routes, no regional airline can operate flights ticketed by DL or NW in these routes. Note that regional airlines operating flights for DL or NW in other routes may be present in the routes of the control group. Then they must operate flights on their behalf or flights ticketed by any other major carrier than DL and NW. For instance Express Jet Airlines (EV) operates many flights for DL, but there can be no route of the control group where this happens, and still this group comprises routes where EV operates flights for United Airlines (UA). We remove 11 routes from the control group where either DL or NW operates flights ticketed by another carrier. In the set of remaining routes, we first select the 1,559 routes where there is at least one carrier that is active each quarter both pre and post-merger. This carrier plays the role of DL in the treated routes. Finally a counterpart 
of NW is found by requiring that the routes of the control group have at least two different carriers always active until the merger announcement. This additional requirement is very demanding: the control group eventually consists of 226 routes only, which corresponds to a 21,192 observation sample.

The full dataset has $412,943+21,192=434,135$ observations of carriers in the selected routes in the sample window.

Table 1: Summary statistics

\begin{tabular}{lccccccccc}
\hline \hline & \multicolumn{3}{c}{ Control } & \multicolumn{5}{c}{ Treatment } \\
Period & Pre merger & post-merger & Pre merger & post-merger \\
& $(1)$ & $(2)$ & $(3)$ & $(4)$ & $(5)$ & $(6)$ & $(7)$ & $(8)$ \\
\hline Nb of quarters & 20 & 20 & 20 & 20 & 20 & 20 & 20 & 20 \\
Nb of routes & 226 & 143 & 226 & 143 & 2353 & 2135 & 2353 & 2135 \\
Distance per route (in km) & 1322 & 1585 & 1322 & 1585 & 2068 & 2007 & 2068 & 2007 \\
Nb of airports & 99 & 81 & 99 & 81 & 137 & 137 & 137 & 137 \\
Nb of different carriers & 18 & 18 & 16 & 14 & 20 & 18 & 16 & 16 \\
Nb of carriers per route and quarter & 2.32 & 2.32 & 2.36 & 2.37 & 4.90 & 4.65 & 3.87 & 3.69 \\
Nb of passengers per route and quarter (period) & 22,589 & 4878 & 20,542 & 5184 & 6,485 & 4736 & 6,575 & 4729 \\
Herfindahl index per route and quarter & 0.63 & 0.63 & 0.67 & 0.66 & 0.37 & 0.38 & 0.46 & 0.47 \\
Homogeneity devices & No & Yes & No & Yes & No & Yes & No & Yes \\
\hline
\end{tabular}

Descriptive statistics about the two groups are given in normal font style in Table 1 . The treatment typically comprises longer routes with less competition and much less passengers. In view of these differences one may find questionable the validity of the common trend assumption. In our setup it is difficult to assess the validity of this assumption since the dependent variable will be computed only once before the merger and once after the merger for each carrier $\times$ route pair. Nevertheless one might argue that this assumption is more likely to hold when the two groups display ex ante greater similarity. To obtain more similar groups we use a nearest neighbor matching algorithm that matches each treated route one at a time to the control route with closest score. The propensity score is computed from a logit model whose all explanatory variables are from 2000:Q1, i.e., three years before the beginning of the pre-merger period. The explanatory variables are the distance of the route, the number of passengers transported in the route, the number of competitors and the Herfindahl index in the route. We have also constrained the number of carriers in 
2000:Q1 to be the same in the treated route and the matched control route. ${ }^{3}$ The matching procedure leads to 83 unmatched routes in the control group, and 218 in the treatment group. The matched subsample has 370,169 observations obtained from 143 routes in the control group and 2135 treated routes. Descriptive statistics about the two groups at the outcome of this procedure are given in italic font style in Table 1. The matching procedure performs rather well.

REMARK 1. Our methodology does not guarantee the absence of connections between the routes of the two groups. In particular some DL/NW competitors are active in the two groups, and some treated and control routes share a common endpoint. We find that 15 over 23 carriers are active in both treated and control routes, yielding multimarket contacts in all the routes of the control group, and in most treated routes. Such contacts possibly influence coordination (Ciliberto and Williams, 2014). They may be potential confounding factors if the DL/NW merger occurs simultaneously with changes in the pattern of multimarket contacts. Virtually all the carriers are involved in multimarket contacts before and after the merger, with no clear changes in the pattern of multimarket contacts. Only America West Airlines (HP) and Spirit Airlines (NK) are involved in multimarket contacts either before or after the merger. America West and US Airways (US) merge during the period under consideration, and US was still involved in multimarket contacts after the DL/NW merger. Spirit Airlines appears in both groups only in the post-merger period, but represents less than $1 \%$ of the passengers transported during this period. The issues implied by the routes in different groups having common endpoints are potentially more worrisome. In the matched dataset 54 airports belong to both groups. All the routes in the control group and $2 / 3$ of the treated routes share one common airport. We did not address this issue specifically. It may be partially handled by the inclusion of a route fixed effect in our econometric specification.

\subsection{Econometric model}

Our measure of 'coordination' volatility is the coefficient of variation CoVar of the number of passengers per carrier and route,

$$
\operatorname{CoVar}_{f r p}=\frac{\sigma_{f r p}}{\bar{q}_{f r p}}
$$

where $\bar{q}_{f r p}$ is the average number of passengers transported by carrier $f$ in route $r$ during period $p$, and

$$
\sigma_{f r p}^{2}=\frac{1}{\# \mathcal{P}(p)-1} \sum_{t \in \mathcal{P}(p)}\left(q_{f r}(t)-\bar{q}_{f r p}\right)^{2},
$$

with $\mathcal{P}(p)$ consisting of the quarters $t$ in period $p$.

\footnotetext{
${ }^{3}$ The estimation is made using the matchit function available for $\mathrm{R}$, with the nearest method, allowing for replacement, a ratio equal to 1 and the constraint of performing an exact matching on the number of carriers in 2000:Q1 covariate.
} 
Our most general econometric model takes the form

$$
\begin{aligned}
\log \left(\operatorname{CoVar}_{f r p}\right)=X_{f p} b_{0}+\mu_{f}+\mu_{r}+\text { Post }_{p} & b_{\text {Post }}+\text { Treated }_{f r} b_{\text {Treat }} \\
& + \text { Post }_{p} \times \text { Treated }_{f r} b_{\text {dd }}+\varepsilon_{f r p} .
\end{aligned}
$$

The regressors include carrier and route fixed effects $\mu_{f}$ and $\mu_{r}$, the Post $_{p}$ variable (equal to 0 when $p=0$ and 1 otherwise), and a Treated fr $_{r}$ variable equal to 0 for all the carriers $f$ in a route $r$ of the control group, and to 1 for all the carriers $f$ in a route $r$ of the treatment group. In our theoretical model firms face the same cost environment whereas the DL/NW merger occurs in a context of sharp increase in oil prices and possibly perturbed labor relations. The vector $X_{f p}$ comprises a constant and two controls for differential cost changes: Pfuel ${ }_{f p}$ gives the fuel price per gallon ${ }^{4}$ and Wage $_{f p}$ the average wage per full time equivalent worker. ${ }^{5,6}$

The coefficient $b_{\mathrm{dd}}$ is the difference-in-differences impact of the merger on the (logarithm of the) coefficient of variation of the number of passengers.

\subsection{Impact of the $\mathrm{DL} / \mathrm{NW}$ merger}

To implement the econometric model we transform the sample so that the unit of observation becomes a triplet (carrier $\times$ route $\times$ period). We are then left with only two observations for each carrier $f$ and route $r$. The first one gives CoVar $f r 0$ and the other $\operatorname{CoVar}_{f r 1}$. This yields a sample of 26,283 observations. We first consider the 'intensive' margin by abstracting from entry and exit firms' decisions. We remove all the observations corresponding to carriers that are active during either the pre or post-merger periods, but not in the two periods (except NW that is present in the pre-merger period only). That is, we examine how volatility changes for carriers that are active both before and after the merger. The resulting full 'intensive' sample has 21,885 observations. The own effect of the extensive (entry/exit) margin will be analyzed in Table 3.

\footnotetext{
${ }^{4}$ This variable is computed from the Air Carrier Financial Reports, Form 41 Financial Data, Schedule $\mathrm{P}-12 \mathrm{a}$, as the ratio between the total fuel cost (in US Dollars) spent on scheduled domestic flights (SDOMTCOST) and the total fuel consumption (in Gallons) on scheduled domestic flights (SDOMT-GALLONS).

${ }^{5}$ It is computed from the same Form 41 Financial Data, now Schedules P-6 and P-1a Employees. It is equal to the ratio of total salaries (SALARIES) in Schedule P-6 and total full-time equivalent employees (EMPFTE) that counts two part-time employees as one full-time employee, given in Schedule P-1a. Both variables are aggregated per period (pre and post-merger).

${ }^{6}$ The theoretical model also supposes given production facilities for every firm. The seat capacity reported in the T-100 database is not a suitable proxy for capacity since it is potentially endogenous. Indeed airlines adjust both frequencies and aircraft (and thus seat capacity) over seasonal cycles. Schedule B-43 Inventory available in Form 41 Financial Data provides an annual inventory of aircraft engines per carrier as well as some details about aircrafts. It is better suited for controlling for firm size, but the data is available from 2006:Q1 only. Since the US/HP merger occurred before 2006, we did not include seat capacity in the illustration. Still we checked that the impact of the DL/NW and UA/CO mergers that both occurred after 2006 are unaffected by the inclusion of this additional control (the results are not reported in the paper).
} 

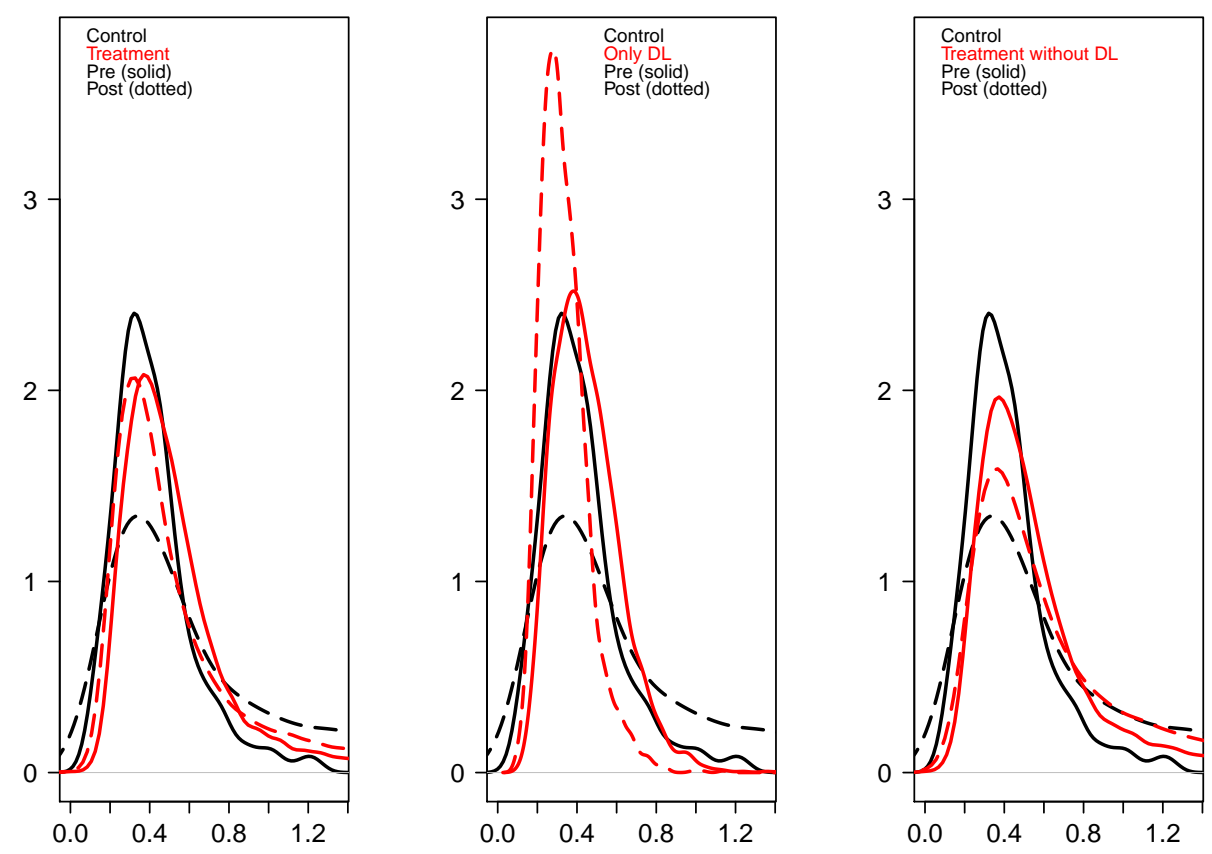

Figure 1: Distribution of CoVar per carrier and route

Figure 1 depicts the distribution of CoVar before the merger announcement (solid line) and after the merger completion (dotted line), for carriers in routes of the control group (in black) and of the treatment group (in red). The right panel considers the whole treatment group. It shows that these routes resisted well the destabilization that occurs in the routes of the control group, with volatility being slightly dampened in the treatment group. The two remaining panels describe the volatility impact for different subsamples of the treatment group. The panel in the middle considers a subsample that only consists of DL observations. The production of this carrier clearly enters a huge stabilization phase following completion. The right panel excludes DL and NW observations and highlights that volatility is just slightly magnified among DL/NW competitors in the treated routes. The difference-indifferences argument thus suggests that stabilization not only concerns DL but also DL/NW competitors, that is all the firms active in the market.

The regression results reported in Table 2 confirm the insights from Figure 1. Columns (1) to (3) apply to the 21,885 observation sample of firms active both before and after the merger observations. For each specification the DL/NW merger caused a significant volatility reduction. The coefficient of variation of the number of passengers transported decreases by $24.7 \%$ in column (3). In this sample NW has $14.9 \%$ market share before the merger, so that the transfer of $1 \%$ market share from a small carrier to a larger one yields a $1.65 \%$ reduction in the firms' production variability. 
Columns (4) to (6) apply to the 18,675 observation sample of the matched firms active both before and after the merger. The coefficient of variation now decreases by $30.5 \%$ in column (6) but NW has $19.9 \%$ market share in this sample. This gives the main result of this illustration: the transfer of $1 \%$ market share from NW to DL implied a $1.53 \%$ reduction in production variability at the firm $\times$ route level.

Table 2: A stabilizing impact of the DL/NW merger

\begin{tabular}{|c|c|c|c|c|c|c|}
\hline & \multicolumn{6}{|c|}{ U } \\
\hline & \multicolumn{3}{|c|}{ Full intensive sample $^{\ddagger}$} & \multicolumn{3}{|c|}{ Matched intensive ${ }^{\ddagger}$ sample } \\
\hline & (1) & $(2)$ & $(3)$ & $(4)$ & (5) & $(6)$ \\
\hline Constant & $\begin{array}{c}-1.005^{* * *} \\
(0.034)\end{array}$ & $\begin{array}{c}0.066 \\
(0.116)\end{array}$ & $\begin{array}{c}-4.213^{* * *} \\
(0.413)\end{array}$ & $\begin{array}{c}-0.906^{* * *} \\
(0.034)\end{array}$ & $\begin{array}{c}-1.193^{* * *} \\
(0.046)\end{array}$ & $\begin{array}{c}-4.372^{* * *} \\
(0.503)\end{array}$ \\
\hline PFuel (log) & & & $\begin{array}{c}-2.282^{* * *} \\
(0.129)\end{array}$ & & & $\begin{array}{c}-2.510^{* * *} \\
(0.161)\end{array}$ \\
\hline Wage $(\log )$ & & & $\begin{array}{c}2.649^{* * *} \\
(0.257)\end{array}$ & & & $\begin{array}{c}2.754^{* * *} \\
(0.311)\end{array}$ \\
\hline Post & $\begin{array}{c}0.183^{* * *} \\
(0.037)\end{array}$ & $\begin{array}{c}0.185^{* * *} \\
(0.039)\end{array}$ & $\begin{array}{c}1.410^{* * *} \\
(0.103)\end{array}$ & $\begin{array}{c}0.244^{* * *} \\
(0.043)\end{array}$ & $\begin{array}{c}0.244^{* * *} \\
(0.046)\end{array}$ & $\begin{array}{c}1.605^{* * *} \\
(0.127)\end{array}$ \\
\hline Treated & $\begin{array}{c}0.300^{* * *} \\
(0.035)\end{array}$ & & & $\begin{array}{c}0.208^{* * *} \\
(0.036)\end{array}$ & & \\
\hline Post $\times$ Treated & $\begin{array}{c}-0.218^{* * *} \\
(0.039)\end{array}$ & $\begin{array}{c}-0.261^{* * *} \\
(0.042)\end{array}$ & $\begin{array}{c}-0.247^{* * *} \\
(0.044)\end{array}$ & $\begin{array}{c}-0.276^{* * *} \\
(0.045)\end{array}$ & $\begin{array}{c}-0.319^{* * *} \\
(0.049)\end{array}$ & $\begin{array}{c}-0.305^{* * *} \\
(0.049)\end{array}$ \\
\hline Route fixed effect & No & Yes & Yes & No & Yes & Yes \\
\hline Carrier fixed effect & No & Yes & Yes & No & Yes & Yes \\
\hline$\underline{\mathrm{Nb} \text { of observations }}$ & 21,885 & 21,885 & 21,885 & 18,675 & 18,675 & 18,675 \\
\hline Notes: & $\begin{array}{l}* * * \text { (resp., } \\
\text { Standard e } \\
\text { Pre merger } \\
\ddagger \text { Full and }\end{array}$ & $\begin{array}{l}\text { and } * \text { Sign } \\
\text { rs are clust } \\
\text { riod: } 2003 \\
\text { tched sam! }\end{array}$ & $\begin{array}{l}\text { ant at the } \\
\text { d at the } r \\
\text { only com }\end{array}$ & $\begin{array}{l}\text { resp., } 5 \text { ar } \\
\text { level. } \\
\text { st-merger } \\
\text { e carriers }\end{array}$ & $\begin{array}{l}\text { 10) percent } \\
\text { riod: } 2010 \text { : } \\
\text { esent both }\end{array}$ & $\begin{array}{l}1 . \\
\text { after the }\end{array}$ \\
\hline
\end{tabular}

In Appendix we provide more details on DL/NW merger. We find that a stabilizing impact for different pre and post-merger periods, provided that the transitory period between announcement and completion is not taken into account. We also find that the merger has a destabilizing impact in the very short run. The gain in stability obtains two years after the completion and then quickly reaches the level reported in Table 2.

In appendix we perform various robustness checks. In particular we find no impact for unbalanced placebo mergers, as well as for the routes where DL does not compete with NW during the pre-merger period. We also find a stabilizing impact for two other important 
mergers of the last decade, the one between US Airways and America West, and the one between United and Continental.

\subsection{Discussion and limits}

Column (1) of Table 3 shows that the merger effect entirely disappears when the postmerger goes from announcement to completion. Column (2) shows that the stabilizing impact reappears, but is mitigated with respect to those reported in Table 2, when the post-merger period starts from announcement and ends in 2015:Q1. These results suggest that the actual transfer of production capacities is a necessary condition for stabilization..$^{7,8}$ In Appendix we analyze the recent merger between Southwest Airlines (WN) and AirTran Airways (FL) completed in 2014:Q4. We find results consistent with this prediction. There is indeed no impact for the merger, with a post-merger period ending at completion.

Columns (3) to (5) take into account the extensive margin by the inclusion of all the carriers active either before or after the merger. Column (4) considers our reference postmerger period starting following the completion. It therefore differs from column (6) in Table 2 by including the carriers exiting the market before the announcement or entering the market after the completion. The impact in column (4) is negative but in this large dataset it is significant at the 10 percent level only, suggesting exits of 'stable' carriers from the control group and/or entries of 'unstable' carriers in the treated routes. With different post-merger periods the extensive entry/exit margin the merger yields no impact on variability of the number of passengers. The lower size of the sample in column (5) is mostly due to entries after completion. These entries imply enough instability in the treated routes to offset the stabilizing impact of the merger reported in column (2).

These early results accord with our theoretical predictions. The stabilizing impact on production only appears following the completion, once productive assets of the two airlines are actually merged; it concerns not only the merging firms but also the other firms present in the market; new entries tend to exacerbate variability. Still our method does not allow us to identify properly changes in the set of rationalizable outcomes. Alternative plausible mechanisms consistent with an equilibrium viewpoint could explain stabilization as well. Some of them have already been discussed above or are discussed in the appendix. Others could involve collusion (merger may facilitate collusion by reducing the number of participants in a market) or sharing of information on uncertain demand (Kalnis, Froeb and

\footnotetext{
${ }^{7}$ Specific features of the airline industry imply that some actions in fact are pre-announced and only gradually committed to over time: details about the flight are taken and announced to passengers well ahead of the actual flight date, and market intelligence data clearinghouses help forming accurate forecasts about competitors' actions. If the DL/NW merger was a surprise in the airline industry, it may also be that carriers cannot easily change their own schedules early in the transitory period.

${ }^{8}$ The sample in column (1) is a subset of the sample in column (2): the sample in column (2) comprises firms exiting during the transitory period but reentering the route after completion. The mitigated impact in column (2) could therefore also result from temporary exits of firms whose behavior displays more inertia after the completion.
} 
Table 3: Limits to the impact of the DL/NW merger

\begin{tabular}{|c|c|c|c|c|c|}
\hline \multirow[b]{3}{*}{ Post-merger period } & \multicolumn{2}{|c|}{ Matched intensive ${ }^{\ddagger}$ sample } & \multicolumn{2}{|l|}{ CoVar } & \multirow{2}{*}{$(5)$} \\
\hline & $(1)$ & $(2)$ & (3) & $(4)$ & \\
\hline & 2008:Q2-2009:Q4 ${ }^{1}$ & 2008:Q2-2015:Q1 ${ }^{2}$ & 2008:Q2-2009:Q4 ${ }^{1}$ & 2010:Q2-2015:Q1 ${ }^{3}$ & 2008:Q2-2015:Q1 ${ }^{2}$ \\
\hline Constant & $\begin{array}{l}-1.777 \\
(1.280)\end{array}$ & $\begin{array}{c}5.337^{* * *} \\
(0.265)\end{array}$ & $\begin{array}{l}-0.808 \\
(1.948)\end{array}$ & $\begin{array}{c}-3.423^{* * *} \\
(0.682)\end{array}$ & $\begin{array}{c}0.248 \\
(0.688)\end{array}$ \\
\hline PFuel (log) & $\begin{array}{l}1.217^{*} \\
(0.654)\end{array}$ & $\begin{array}{c}-2.366^{* * *} \\
(0.144)\end{array}$ & $\begin{array}{c}0.182 \\
(0.831)\end{array}$ & $\begin{array}{c}-2.075^{* * *} \\
(0.252)\end{array}$ & $\begin{array}{c}-2.487^{* * *} \\
(0.189)\end{array}$ \\
\hline Wage $(\log )$ & $\begin{array}{c}0.034 \\
(0.878)\end{array}$ & $\begin{array}{c}-3.783^{* * *} \\
(0.184)\end{array}$ & $\begin{array}{c}0.020 \\
(1.299)\end{array}$ & $\begin{array}{c}2.320^{* * *} \\
(0.444)\end{array}$ & $\begin{array}{l}-0.380 \\
(0.458)\end{array}$ \\
\hline Post & $\begin{array}{c}-0.318^{* *} \\
(0.151)\end{array}$ & $\begin{array}{c}2.677^{* * *} \\
(0.104)\end{array}$ & $\begin{array}{l}-0.096 \\
(0.209)\end{array}$ & $\begin{array}{c}1.405^{* * *} \\
(0.224)\end{array}$ & $\begin{array}{c}2.092^{* * *} \\
(0.243)\end{array}$ \\
\hline Post $\times$ Treated & $\begin{array}{c}0.161 \\
(0.098)\end{array}$ & $\begin{array}{c}-0.159^{* * *} \\
(0.044)\end{array}$ & $\begin{array}{c}0.129 \\
(0.141)\end{array}$ & $\begin{array}{c}-0.251^{*} \\
(0.129)\end{array}$ & $\begin{array}{c}0.057 \\
(0.174)\end{array}$ \\
\hline $\begin{array}{l}\text { Route fixed effect } \\
\text { Carrier fixed effect } \\
\text { Nb of observations }\end{array}$ & $\begin{array}{c}\text { Yes } \\
\text { Yes } \\
33,348\end{array}$ & $\begin{array}{c}\text { Yes } \\
\text { Yes } \\
11,033\end{array}$ & $\begin{array}{c}\text { Yes } \\
\text { Yes } \\
35,638\end{array}$ & $\begin{array}{c}\text { Yes } \\
\text { Yes } \\
22,481\end{array}$ & $\begin{array}{c}\text { Yes } \\
\text { Yes } \\
13,108\end{array}$ \\
\hline Notes: & $\begin{array}{l}* * * \text { (resp., }{ }^{* *} \text { and } \\
\text { Standard errors are } \\
\ddagger \text { The sample only } \\
\dagger \text { The sample comp } \\
\text { 1. Pre merger perio } \\
\text { 2. Pre merger perio } \\
\text { 3. Pre merger perio }\end{array}$ & $\begin{array}{l}\text { fignificant at the } 1 \\
\text { lustered at the route } \\
\text { mprises matched cal } \\
\text { ses all the matched } \\
\text { 2006:Q2-2007:Q4. } \\
\text { 2001:Q1-2007:Q4. } \\
\text { 2003:Q1-2007:Q4. }\end{array}$ & $\begin{array}{l}\text { sp., } 5 \text { and } 10) \text { perce } \\
\text { evel. } \\
\text { ers present both bef } \\
\text { rriers present during }\end{array}$ & $\begin{array}{l}\text { evel. } \\
\text { and after the mer } \\
\text { e quarter at least }\end{array}$ & the sample window. \\
\hline
\end{tabular}

Tschantz, 2010). More should thus be done to assess the plausibility of the rationalizability viewpoint.

\section{Conclusion}

Considering rationalizable outcomes affects usual recommendations made in competition policy when the competitive outcome is not dominant solvable. In this case, the market should sometimes involve few firms, each one endowed with similar production capacities. We find that market power 'stabilizes' Nash equilibrium production by favoring dominance solvability of the equilibrium. This implies a trade-off between stability and efficiency: Asymmetry results both in a lower consumers' surplus in equilibrium and a gain in the likelihood that the equilibrium be reached.

Robustness checks could tackle the following issues:

1. The flavor of the results is that instability is favored by model primitives discouraging entries. A typical example involves entry fixed costs. If these costs are large enough to deter entry of a firm expecting all the others to produce their monopoly production, then the 'no production' decision is rationalizable (which implies that the monopoly 
production is rationalizable as well, $\left.\left[q_{\ell}^{\mathrm{inf}}, q_{\ell}^{\mathrm{sup}}\right]=\left[0, q_{\ell}^{m}\right]\right)$. This argument is robust: it relies neither on symmetry nor on linearity. In addition, entry fixed costs may yield equilibrium multiplicity, which implies failure of global dominance solvability (the set of rationalizable solutions always includes all the equilibria).

2. Our results can be extended to a general linear anonymous game. In such a game, the best-response map is

$$
R_{\ell}\left(Q_{-\ell}\right)=\left\{\begin{array}{cl}
a\left(N_{\ell}\right)-b\left(N_{\ell}\right) Q_{-\ell} & \text { if } Q_{-\ell} \leq a\left(N_{\ell}\right) / b\left(N_{\ell}\right) \\
0 & \text { if } Q_{-\ell} \geq a\left(N_{\ell}\right) / b\left(N_{\ell}\right)
\end{array}\right.
$$

In the Cournot game, $a=\delta_{0} b / \delta$. Since our results rely on first and second derivatives of these two two functions, by continuity, they still hold when $a$ and $b$ are close in the $C^{2}$-topology.

3. Our analysis abstracts from the possibility of collusion among firms. Firms' homogeneity is known to favor collusion (Compte et al., 2002). Our results can therefore be thought of as another illustration of the fragility of the equilibrium with identical firms. Still, the issue of rationalizability and collusion would be worth to study. On the one hand, it is possible that the market never reaches the equilibrium when firms have similar production facilities, because the market outcome is a rationalizable outcome different from the Cournot equilibrium, so that collusion does not arise. On the other hand, collusion maintains asymmetries across firms, and may therefore preserve dominance solvability of the equilibrium.

4. In our analysis, the asset distribution is exogenous. A market for the assets may possibly preserve dominance solvability of the equilibrium. If, for instance, firms with a higher stock of assets are more likely to acquire new assets, because e.g., the assets can also be used as collateral, then a market for productive assets favors asymmetries across firms, and thus dominance solvability of the equilibrium. 


\section{References}

[1] Amir, R., 1996, Cournot Oligopoly and the Theory of Supermodular Games, Games and Economic Behavior, 15, 132-148.

[2] Basu, K., 1992, A characterization of the class of rationalizable equilibria of oligopoly games, Economics Letters 40, 187-191.

[3] Bernheim, B., 1984, Rationalizable strategic behavior, Econometrica 52, 1007-28.

[4] Borenstein, S., 1990, Airline mergers, airport dominance, and market power, American Economic Review 80(2), 400-404.

[5] Borenstein, S. and N. Rose, 1994, Competition and price dispersion in the U.S. airline industry, Journal of Political Economy 102, 653-683.

[6] Börgers, T. and M. Janssen, 1995, On the dominance solvability of large Cournot games, Games and Economic Behavior 8, 297-321.

[7] Ciliberto, F. and E. Tamer, 2009, Market structure and multiple equilibria in airline markets, Econometrica 77, 1791-1828.

[8] Ciliberto, F. and J. Williams, 2010, Limited Access to Airport Facilities and Market Power in the Airline Industry, Journal of Law and Economics 53 (2010), 467-495.

[9] Compte, O., F. Jenny and P. Rey, 2002, Collusion, mergers and capacity constraints, European Economic Review 46, 1-29.

[10] Davis, L. and C. Wolfram, 2011, Deregulation, consolidation, and efficiency: evidence from U.S. nuclear industry, NBER working paper 17341.

[11] Durieu, P., P. Solal and O. Tercieux, 2011, Adaptive learning and p-best response sets, International Journal of Game Theory 40, 735-747.

[12] Esponda, I., 2013, Rationalizable conjectural equilibrium: A framework for robust predictions, Theoretical Economics, 8, 467-501.

[13] Farrell, J. and C. Shapiro, 1990, Asset ownership and market structure in oligopoly, Rand Journal of Economics 21, 275-292.

[14] Forbes, S.J. and M. Lederman, 2009, Adaptation and vertical integration in the airline industry, American Economic Review 99, 1831-1849.

[15] Gaballo, G., 2013, Market power, expectational instability and welfare, mimeo.

[16] Gerardi, K. and A.H. Shapiro, Does competition reduce price dispersion? New evidence from the airline Industry, Journal of Political Economy 117, 1-37. 
[17] Gugler, K., D.C. Mueller, B.B. Yurtoglu and C. Zulehner, 2003, The effects of mergers: an international comparison, International Journal of Industrial Organization 21, 625653.

[18] Guesnerie, R., 1992, An exploration of the eductive justifications of the rationalexpectations hypothesis, American Economic Review 82, 1254-78.

[19] Guesnerie, R., 1993, Theoretical tests of the rational expectations hypothesis in economic dynamical models, Journal of Economic Dynamics and Control 17, 847-864.

[20] Hommes, C. and F. Wagener, 2010, Does eductive stability imply evolutionary stability?, Journal of Economic Behavior and Organization 75, 25-39.

[21] Kalnins, A., L. Froeb and S Tschantz, 2010, Mergers increase output when firms compete by managing revenue, Vanderbilt Law and Economics Research Paper.

[22] Kim, E. and V. Singal, 1993, Mergers and Market Power: Evidence from the Airline Industry, American Economic Review 83, 549-569.

[23] Marx, L., 1999, Adaptive Learning and Iterated Weak Dominance, Games and Economic Behavior 26, 253-278.

[24] Milgrom, P., and J. Roberts, 1990, Rationalizability, learning, and equilibrium in games with strategic complementarities, Econometrica, 58, 1255-1277.

[25] Moulin, H., 1984, Dominance solvability and Cournot stability, Mathematical Social Science 7, 83-102.

[26] Perry, M. and M. Porter, 1985, Oligopoly and the incentive for horizontal merger, American Economic Review 75, 219-227.

[27] Rubinstein, A., and A. Wolinsky, 1994, Rationalizable conjectural equilibrium: Between Nash and rationalizability, Games and Economic Behavior, 6, 299-311.

[28] Town, R., D. Wholey, R. Feldman, L.R. Burns, 2006, The welfare consequences of hospital mergers, NBER working paper 12244.

[29] Vives, X., 1990, Nash Equilibrium with Strategic Complementarities, Journal of Mathematical Economics, 19(3), 305-321.

[30] Vives, X., 1999, Oligopoly Pricing: Old Ideas and New Tools, MIT Press.

[31] Williamson, O., 1968, Economies as and antitrust defense: The welfare trade-offs, American Economic Review, 58(1), 18-36. 


\section{Appendix}

\section{A Proof of Lemmas 2 and 3}

Let $L_{0}$ be the set of values of $\ell$ such that $q_{\ell}^{\text {inf }}=0$. The relations (4) give:

$$
\begin{aligned}
\forall \ell \notin L_{0} \quad, \quad q_{\ell}^{\text {inf }} & =b_{\ell}\left(\frac{\delta_{0}}{\delta}-\left(Q^{\text {sup }}-q_{\ell}^{\text {sup }}\right)\right), \\
\forall \ell \in L_{0} \quad, \quad q_{\ell}^{\text {inf }} & =0, \\
\forall \ell \quad, \quad q_{\ell}^{\text {sup }} & =b_{\ell}\left(\frac{\delta_{0}}{\delta}-\left(Q^{\text {inf }}-q_{\ell}^{\text {inf }}\right)\right) .
\end{aligned}
$$

Solving for $q_{\ell}^{\text {inf }}$ and $q_{\ell}^{\text {sup }}$ gives

$$
\begin{aligned}
& \forall \ell \notin L_{0} \quad, \quad q_{\ell}^{\text {inf }}=\frac{b_{\ell}^{2}}{1-b_{\ell}^{2}}\left(\frac{\delta_{0}}{\delta}-Q^{\text {inf }}\right)+\frac{b_{\ell}}{1-b_{\ell}^{2}}\left(\frac{\delta_{0}}{\delta}-Q^{\text {sup }}\right), \\
& \forall \ell \notin L_{0} \quad, \quad q_{\ell}^{\text {sup }}=\frac{b_{\ell}}{1-b_{\ell}^{2}}\left(\frac{\delta_{0}}{\delta}-Q^{\text {inf }}\right)+\frac{b_{\ell}^{2}}{1-b_{\ell}^{2}}\left(\frac{\delta_{0}}{\delta}-Q^{\text {sup }}\right), \\
& \forall \ell \in L_{0} \quad, \quad q_{\ell}^{\text {sup }}=b_{\ell}\left(\frac{\delta_{0}}{\delta}-Q^{\text {inf }}\right),
\end{aligned}
$$

and $\forall \ell \in L_{0}, q_{\ell}^{\text {inf }}=0$. Summing over $\ell$ gives a linear system in $Q^{\text {inf }}$ and $Q^{\text {sup }}$ whose solution is ( 7$)$, namely:

$$
Q^{\mathrm{inf}}=\left(1+\frac{c-a}{a^{2}-c(c+e)}\right) \frac{\delta_{0}}{\delta}, \quad Q^{\mathrm{sup}}=Q^{\mathrm{inf}}+\frac{e}{a^{2}-c(c+e)} \frac{\delta_{0}}{\delta},
$$

with

$$
a=1+\sum_{\ell \notin L_{0}} \frac{b_{\ell}^{2}}{1-b_{\ell}^{2}}, c=\sum_{\ell \notin L_{0}} \frac{b_{\ell}}{1-b_{\ell}^{2}} \text { and } e=\sum_{\ell \in L_{0}} b_{\ell} .
$$

For every $\ell \in L_{0}, q_{\ell}^{\text {inf }}=0$ so that $\sum_{k \neq \ell} q_{k}^{\text {sup }}>\delta_{0} / \delta$. Using (13), (14) and the expressions of $Q^{\text {inf }}$ and $Q^{\text {sup }}$, this latter inequality is equivalent to:

$$
\frac{(c-a)\left(b_{m}+1\right)+e}{a^{2}-c(e+c)}>0 .
$$

Since $e \geq 0$ and

$$
Q^{\text {sup }}-Q^{\mathrm{inf}}=\frac{e}{a^{2}-c(e+c)} \frac{\delta_{0}}{\delta} \geq 0,
$$

it follows that $a^{2}-c^{2}-c e>0$, so that the inequality (15) is equivalent to

$$
(a-c)\left(b_{m}+1\right)<e
$$


which is equivalent to (6) since

$$
c-a=\sum_{k \notin L_{0}} \frac{b_{k}}{1+b_{k}}-1 .
$$

Hence, $q_{\ell}^{\text {inf }}=0$ if and only if (6) does not hold true. Since the LHS of (6) is increasing in $\ell$, there is a value $\bar{\ell}$ such that $q_{\ell}^{\text {inf }}=0$ if and only if $\ell>\bar{\ell}$.

\section{B Proof of Proposition 4}

Let $d N_{h}=-d N_{s}<0$. By (2), $b_{\ell}$ is increasing and concave in $N_{\ell}$. Hence we have $d b_{h}<$ $0<d b_{s}$ and $d b_{h}+d b_{s}>0$. Differentiating (16) gives:

$$
d Q^{\text {sup }}-d Q^{\mathrm{inf}}=\frac{\delta_{0}}{\delta} d\left(\frac{e}{a^{2}-c(c+e)}\right) .
$$

We distinguish between 3 cases for the computation of $d Q^{\text {sup }}-d Q^{\text {inf }}$.

Case 1: $\bar{\ell}<h<s$. $a$ and $c$ remain constant and (18) writes:

$$
d Q^{\text {sup }}-d Q^{\inf }=\frac{\delta_{0}}{\delta} \frac{a^{2}-c^{2}}{\left(a^{2}-c(c+e)\right)^{2}} d e,
$$

where $d e=d b_{h}+d b_{s}>0$. Since $a^{2}-c^{2}=(a-c)(a+c)$, simple algebra allows us to check that the above numerator is positive so that $d Q^{\text {sup }}-d Q^{\text {inf }}>0$.

Case 2: $h<s \leq \bar{\ell}$. e remains constant and (18) writes:

$$
d Q^{\text {sup }}-d Q^{\text {inf }}=-\frac{\delta_{0}}{\delta} \frac{e}{\left(a^{2}-c(c+e)\right)^{2}}(2 a d a-(2 c+e) d c) .
$$

This has the same sign as $((2 c+e) d c-2 a d a)$. It is positive if and only if

$$
\left(c+\frac{1}{2} e\right) \sum_{\ell \leq \bar{\ell}} d\left(\frac{b_{\ell}}{1-b_{\ell}^{2}}\right)>a \sum_{\ell \leq \bar{\ell}} d\left(\frac{b_{\ell}^{2}}{1-b_{\ell}^{2}}\right) .
$$

On the one hand, $\frac{b_{\ell}}{1+b_{\ell}}$ is increasing and concave in $N_{\ell}$, which implies

$$
\sum_{\ell \leq \bar{\ell}} d\left(\frac{b_{\ell}}{1+b_{\ell}}\right)>0 .
$$

This latter inequality rewrites

$$
\sum_{\ell \leq \bar{\ell}} d\left(\frac{b_{\ell}}{1-b_{\ell}^{2}}\right)>\sum_{\ell \leq \bar{\ell}} d\left(\frac{b_{\ell}^{2}}{1-b_{\ell}^{2}}\right),
$$


The LHS is positive since $\frac{b_{\ell}}{1-b_{\ell}^{2}}$ is shown to be increasing and concave in $N_{\ell}$ (but the RHS cannot be signed because $\frac{b_{\ell}^{2}}{1-b_{\ell}^{2}}$ is neither concave nor convex in $N_{\ell}$ ). If the RHS is negative, then (20) implies that (19) holds true. If the RHS is positive, then rewriting (17) for $\bar{\ell}$ gives

$$
a-c>\frac{e}{1+b_{\bar{\ell}}},
$$

which implies $c+\frac{1}{2} e<a$. Combining this latter inequality with (20) proves that (19) holds true. This shows that $d Q^{\text {sup }}-d Q^{\text {inf }}>0$.

Case 3: $h \leq \bar{\ell}<s$. (18) writes:

$$
\begin{aligned}
d Q^{\text {sup }}-d Q^{\text {inf }}= & -\frac{\delta_{0}}{\delta} \frac{e}{\left(a^{2}-c(c+e)\right)^{2}}(2 a d a-(2 c+e) d c) \\
& +\frac{\delta_{0}}{\delta} \frac{a^{2}-c^{2}}{\left(a^{2}-c(c+e)\right)^{2}} d e
\end{aligned}
$$

$d Q^{\text {sup }}-d Q^{\text {inf }}$ has the same sign as

$$
\begin{gathered}
-e(2 a d a-(2 c+e) d c)+\left(a^{2}-c^{2}\right) d e \\
=e \frac{(2 c+e)\left(1+b_{h}^{2}\right)-4 a b_{h}}{\left(1-b_{h}\right)^{2}\left(1+b_{h}\right)^{2}} d b_{h}+\left(a^{2}-c^{2}\right) d b_{s}
\end{gathered}
$$

Since $d b_{s}>0>d b_{h}$ and $d b_{h}+d b_{s}>0$, the above expression is positive if

$$
e \frac{(2 c+e)\left(1+b_{h}^{2}\right)-4 a b_{h}}{\left(1-b_{h}\right)^{2}\left(1+b_{h}\right)^{2}}<\left(a^{2}-c^{2}\right)
$$

Inequality $(21)$ implies $(h \leq \bar{\ell})$ :

$$
a-c>\frac{e}{1+b_{\bar{\ell}}} \geq \frac{e}{1+b_{h}}>0 .
$$

Using $\left(a^{2}-c^{2}\right)=(a-c)(a+c)$ a sufficient condition for Inequality (22) is

$$
e \frac{(2 c+e)\left(1+b_{h}^{2}\right)-4 a b_{h}}{\left(1-b_{h}\right)^{2}\left(1+b_{h}\right)^{2}}<(a+c) \frac{1}{1+b_{h}} e \text {. }
$$

This rewrites:

$$
(2 c+e)\left(1+b_{h}^{2}\right)-4 a b_{h}<(a+c)\left(1-b_{h}\right)^{2}\left(1+b_{h}\right) .
$$

Using again Inequality $(23)\left(e<(a-c)\left(1+b_{h}\right)\right)$, a sufficient condition for the above inequality is

$$
\left(2 c+(a-c)\left(1+b_{h}\right)\right)\left(1+b_{h}^{2}\right)-4 a b_{h}<(a+c)\left(1-b_{h}\right)^{2}\left(1+b_{h}\right) .
$$

This rewrites

$$
\begin{aligned}
2 a b_{h}\left(b_{h}-1\right) & <-c 2 b_{h}^{2}\left(1-b_{h}\right), \\
a & >c b_{h} .
\end{aligned}
$$

Since $a-c>0, a>c>c b_{h}$. This shows $d Q^{\text {sup }}-d Q^{\text {inf }}>0$. 


\section{Proof of Proposition 5}

We maximize $Q^{*}$ subject to (8) and (9) in three steps. Since $Q^{*}$ is increasing in $S$ (see (3)), the optimization problem is to maximize $S$ subject to (8) and (9).

Step 1. Consider the Lagrangian:

$$
\sum_{\ell=1}^{M} \frac{\sigma \delta N_{\ell}}{\sigma \delta N_{\ell}+1}+\mu\left(1-\sum_{\ell=1}^{M} \frac{\sigma \delta N_{\ell}}{3 \sigma \delta N_{\ell}+1}\right)+\eta\left(N-\sum_{\ell=1}^{M} N_{\ell}\right) .
$$

It is the Lagrangian associated with the maximization problem for a given value of $M$. Any solution to the initial optimization problem satisfies the first-order conditions in $N_{\ell}$ associated with this Lagrangian. The first-order conditions in $N_{\ell}$ are:

$$
\sigma \delta P\left(\sigma \delta N_{\ell}\right)=0, \text { for every } \ell,
$$

where

$$
P(x)=\frac{1}{(1+x)^{2}}-\mu \frac{1}{(1+3 x)^{2}}-\frac{\eta}{\sigma \delta} .
$$

Hence, the number of different firms (different values of $N_{\ell}$ ) at a solution of the optimization problem equals the number of positive roots of $P$. Observe that

$$
P^{\prime}(x)=-\frac{2}{(1+x)^{3}}+\mu \frac{6}{(1+3 x)^{3}} \text {. }
$$

Since $P^{\prime}(x) \geq 0$ rewrites

$$
\left(3-(3 \mu)^{1 / 3}\right) x \leq(3 \mu)^{1 / 3}-1,
$$

$P^{\prime}$ can change its sign at most once. Hence, either $P$ is monotonic or $P$ admits one local extremum. It follows that $P$ admits at most 2 positive roots: the solution to the optimization problem involves at most two types of firms.

Denote $i=1,2$ the type of a firm. Let $M_{i}$ the number of firms of type $i(i=1,2)$. Every type $i$ firm uses $N_{i}$ assets $\left(0 \leq N_{1} \leq N_{2}\right.$ w.l.o.g.).

Step 2. We maximize $S$ for given $N_{1}$ and $N_{2}$ under the 2 constraints (8) and (9). $S$ is linear in $M_{1}$ and $M_{2}$ :

$$
S=M_{1} \frac{\sigma \delta N_{1}}{\sigma \delta N_{1}+1}+M_{2} \frac{\sigma \delta N_{2}}{\sigma \delta N_{2}+1} .
$$

The stability constraint (8) is linear:

$$
M_{1} \leq \frac{3 \sigma \delta N_{1}+1}{\sigma \delta N_{1}}-\frac{N_{2}}{N_{1}} \frac{3 \sigma \delta N_{1}+1}{3 \sigma \delta N_{2}+1} M_{2}
$$

and the feasibility constraint (9) is linear too:

$$
M_{1} \leq \frac{N}{N_{1}}-\frac{N_{2}}{N_{1}} M_{2}
$$


The marginal rate of substitution of $S$ is $\frac{\frac{\sigma \delta N_{2}}{\sigma \delta N_{2}+1}}{\frac{\sigma \delta N_{1}}{\sigma \delta N_{1}+1}}$, it lies between the slopes of the constraints:

$$
\frac{N_{2}}{N_{1}} \frac{3 \sigma \delta N_{1}+1}{3 \sigma \delta N_{2}+1}<\frac{\frac{\sigma \delta N_{2}}{\sigma \delta N_{2}+1}}{\frac{\sigma \delta N_{1}}{\sigma \delta N_{1}+1}}<\frac{N_{2}}{N_{1}} .
$$

Thus, we have 3 cases:

Case 1: $N_{1} \geq \frac{\sigma \delta N-1}{3 \sigma \delta}$. Then

$$
\frac{3 \sigma \delta N_{1}+1}{\sigma \delta N_{1}} \geq \frac{N}{N_{1}}
$$

and the feasibility constraint is the only relevant constraint (i.e., feasibility implies stability). The solution is $M_{2}=0, M_{1}=N / N_{1}$. The value of $S$ is

$$
\frac{\sigma \delta N}{\sigma \delta N_{1}+1}
$$

Case 2: $N_{2} \leq \frac{\sigma \delta N-1}{3 \sigma \delta}$. Then,

$$
\frac{3 \sigma \delta N_{2}+1}{\sigma \delta N_{2}} \leq \frac{N}{N_{2}}
$$

and the stability constraint is the only relevant constraint (i.e., stability implies feasibility). The solution is $M_{1}=0, M_{2}=\frac{3 \sigma \delta N_{2}+1}{\sigma \delta N_{2}}$. The value of $S$ is

$$
\frac{3 \sigma \delta N_{2}+1}{\sigma \delta N_{2}+1}
$$

Case 3: $N_{1}<\frac{\sigma \delta N-1}{3 \sigma \delta}<N_{2}$. The 2 constraints are relevant. The solution is at the unique intersection between the constraints, namely

$$
\left.\left\{\begin{array}{l}
M_{1}=\frac{1}{N_{2}-N_{1}} \frac{3 \sigma \delta N_{1}+1}{3 \sigma \delta N_{1}}\left(\frac{3 \sigma \delta N_{2}+1}{\sigma \delta}-N\right) \\
M_{2}=\frac{1}{N_{2}-N_{1}} \frac{3 \sigma \delta N_{2}+1}{3 \sigma \delta N_{2}}
\end{array}\right\} N-\frac{3 \sigma \delta N_{1}+1}{\sigma \delta}\right)
$$

The value of $S$ is (after some computations):

$$
\frac{\sigma \delta N_{1}\left(1+3 \sigma \delta N_{2}\right)+\sigma \delta N_{2}+\frac{2 \sigma \delta N+1}{3}}{\left(\sigma \delta N_{1}+1\right)\left(\sigma \delta N_{2}+1\right)} .
$$

Step 3. We solve for $N_{1}$ and $N_{2}$ maximizing $S$ in each of the 3 above cases. 
Case 1. Maximizing $S$ amounts to minimize $N_{1}$. If $\sigma \delta N \leq 1$, then the solution is $N_{1}=0$ and $M_{1}=+\infty\left(M_{2}=0\right)$ and the aggregate production is $\sigma \delta N$ (we are in the competitive case). If $\sigma \delta N>1$, then the solution is $N_{1}=\frac{\sigma \delta N-1}{3 \sigma \delta}$ and

$$
\begin{aligned}
M_{1} & =\frac{3 \sigma \delta N}{\sigma \delta N-1}, \\
S & =\frac{3 \sigma \delta N}{\sigma \delta N+2} .
\end{aligned}
$$

The aggregate production is

$$
Q^{*}=\frac{S}{1+S} \frac{\delta_{0}}{\delta}=\frac{1}{2} \frac{3 \sigma \delta N}{1+2 \sigma \delta N} \frac{\delta_{0}}{\delta}
$$

Case 2. (this case requires $\sigma \delta N>1$ ) Maximizing $S$ amounts to maximize $N_{2}$. The solution is

$$
N_{2}=\frac{\sigma \delta N-1}{3 \sigma \delta}
$$

this is the same solution as Case 1.

Case 3. (this case requires $\sigma \delta N>1$ ). The derivatives of $S$ w.r.t. $N_{1}$ and $N_{2}$ have the following signs:

$$
\begin{aligned}
\frac{\partial S}{\partial N_{1}} & \sim 3 \sigma \delta N_{2}-N \sigma \delta+1>3 \sigma \delta \frac{\sigma \delta N-1}{3 \sigma \delta}-N \sigma \delta+1=0 \\
\frac{\partial S}{\partial N_{2}} & \sim 3 \sigma \delta N_{1}-N \sigma \delta+1<3 \sigma \delta \frac{\sigma \delta N-1}{3 \sigma \delta}-N \sigma \delta+1=0 .
\end{aligned}
$$

$S$ is increasing in $N_{1}$ and decreasing in $N_{2}$. At the optimum,

$$
N_{1}=N_{2}=\frac{\sigma \delta N-1}{3 \sigma \delta}
$$

This is again the same solution as Case 1.

Summing up the 3 cases:

- If $\sigma \delta N \leq 1$, then Case 1 is the only possible case and the solution is that $N$ is divided equally across an infinite number of firms (competitive market).

- If $\sigma \delta N>1$, then the 3 cases give the same solution: a symmetric oligopoly with $\frac{3 \sigma \delta N}{\sigma \delta N-1}$ firms and where each firm owns the same number $\frac{\sigma \delta N-1}{3 \sigma \delta}$ of assets. The aggregate production is $\frac{1}{2} \frac{3 \sigma \delta N}{1+2 \sigma \delta N} \frac{\delta}{\delta_{0}}$. One easily checks that both constraints (8) and (9) are binding. 


\section{Proof of Proposition 6}

The expression (7) of $Q^{\text {inf }}$ implies:

$$
\frac{1}{1-\frac{\delta}{\delta_{0}} Q^{\mathrm{inf}}}=1+\sum_{\ell \leq \bar{\ell}} \frac{b_{\ell}}{1-b_{\ell}}+\frac{\left(\sum_{\ell \leq \bar{\ell}} \frac{b_{\ell}}{1-b_{\ell}^{2}}\right) \sum_{\ell>\bar{\ell}} b_{\ell}}{\sum_{\ell \leq \bar{\ell}} \frac{b_{\ell}}{1+b_{\ell}}-1} .
$$

By definition of $\bar{\ell}$ and Lemma 2, we have

$$
\sum_{\ell \leq \bar{\ell}} \frac{b_{\ell}}{1+b_{\ell}}<\sum_{\ell \leq \bar{\ell}} \frac{b_{\ell}}{1+b_{\ell}}+\sum_{\ell>\bar{\ell}} \frac{b_{\ell}}{1+b_{\bar{\ell}}} \leq 1,
$$

where the strict inequality comes from the equilibrium being unstable. Hence

$$
\sum_{\ell \leq \bar{\ell}} \frac{b_{\ell}}{1+b_{\ell}}-1<0
$$

and

$$
\frac{1}{1-\frac{\delta}{\delta_{0}} Q^{\mathrm{inf}}} \leq 1+\sum_{\ell \leq \bar{\ell}} \frac{b_{\ell}}{1-b_{\ell}}
$$

From (10), we have

$$
\frac{1}{1-\frac{\delta}{\delta_{0}} Q^{* *}}=2 \frac{1+2 \sigma \delta N}{2+\sigma \delta N}
$$

Since every aggregate production $\left(Q^{\mathrm{inf}}\right.$ or $\left.Q^{* *}\right)$ is smaller than $\frac{\delta_{0}}{\delta}$, we have:

$$
Q^{\mathrm{inf}}<Q^{* *} \Leftrightarrow \frac{1}{1-\frac{\delta}{\delta_{0}} Q^{\inf }}<\frac{1}{1-\frac{\delta}{\delta_{0}} Q^{* *}} .
$$

A sufficient condition for this last inequality is

$$
1+\sum_{\ell \leq \bar{\ell}} \frac{b_{\ell}}{1-b_{\ell}}<2 \frac{1+2 \sigma \delta N}{2+\sigma \delta N}
$$

Let $\alpha_{\ell}=N_{\ell} / N \geq 0$ ( $\alpha_{\ell}$ decreasing in $\ell$ and $\sum \alpha_{\ell}=1$ ). Using the definition (2) of $b_{\ell},(24)$ rewrites

$$
\sum_{\ell \leq \bar{\ell}} \frac{\sigma \delta \alpha_{\ell} N}{\sigma \delta \alpha_{\ell} N+1}<\frac{3 \sigma \delta N}{\sigma \delta N+2}
$$

Note that $f\left(\alpha_{\ell}\right)=\frac{\sigma \delta \alpha_{\ell} N}{\sigma \delta \alpha_{\ell} N+1}$ is concave in $\alpha_{\ell}$ so that (Jensen inequality)

$$
\sum_{\ell \leq \bar{\ell}} \frac{f\left(\alpha_{\ell}\right)}{\sum_{\ell \leq \bar{\ell}} \alpha_{\ell}} \leq f\left(\frac{\sum_{\ell \leq \bar{\ell}} \alpha_{\ell}}{\sum_{\ell \leq \bar{\ell}} \alpha_{\ell}}\right)=f(1) .
$$


This rewrites

$$
\sum_{\ell \leq \bar{\ell}} f\left(\alpha_{\ell}\right) \leq \frac{\sigma \delta N}{\sigma \delta N+1} \sum_{\ell \leq \bar{\ell}} \alpha_{\ell}
$$

Since $\sum_{\ell \leq \bar{\ell}} \alpha_{\ell} \leq 1$ and

$$
\frac{\sigma \delta N}{\sigma \delta N+1}<\frac{3 \sigma \delta N}{\sigma \delta N+2}
$$

this implies

$$
\sum_{\ell \notin L_{0}} f\left(\alpha_{\ell}\right)<\frac{3 \sigma \delta N}{\sigma \delta N+2},
$$

which shows that (25) holds true.

\section{E Empirical illustration}

\section{E.1 Alternative treatment and placebo mergers}

The theoretical model predicts no impact on volatility in markets where NW does not compete with DL before the merger. To test this prediction, we select a new treatment group consisting of the routes where DL is active each quarter whereas NW is never present. The control group is unchanged, except that now we require that only one carrier be active each quarter during the full time window. We then run the same matching procedure as in the main text. The results reported in column (1) of Table 4 show no volatility impact of the merger.

In order to assess for a possible mechanical effect due to the post-merger reduction in the number of suppliers we consider two variants. In the first one we remove from the final matched subsample all the observations corresponding to DL and NW. The results reproduced in column (2) of Table 4 show that stabilization still occurs in the sample consisting of DL/NW competitors only. ${ }^{9}$ In the second variant we impute to DL all the flights ticketed by NW before the merger (which removes NW in the pre-merger period). Column (3) shows that stabilization still obtains in this case. ${ }^{10}$

Finally we also consider placebo mergers with unbalanced route characteristics. Columns (4) and (5) of Table 4 report the results for two such mergers. The first one is between American Airlines (AA) and Continental (CO) and follows the chronology of the actual merger between United (UA) and CO, i.e., announced in 2008:Q1 and completed in 2011:Q4. The

\footnotetext{
${ }^{9}$ Airlines do not supply quantities on city-pair routes, but instead they supply quantities on airportpair segments. After the merger the opportunity cost of allocating a seat on a segment to a passenger is determined from a larger set of post-merger routes that include the segment. This could make routes more stable in equilibrium. The impact reported in column (2) in the absence of DL and NW suggests that stabilization at least partly proceeds from different channels.

${ }^{10}$ The results in Table 4 apply to the 'intensive' margin, with all the observations corresponding to carriers present both before and after the merger. They are therefore not driven by additional post-merger competitor entry or exit induced by the merger.
} 
second one is between DL and UA and follows the chronology of the actual DL/NW merger. We find no volatility impact for these mergers. ${ }^{11}$

Table 4: Robustness checks

\begin{tabular}{|c|c|c|c|c|c|}
\hline & \multicolumn{5}{|c|}{ CoVar } \\
\hline & $\begin{array}{c}\text { DL without } \mathrm{NW}^{2} \\
(1)\end{array}$ & $\begin{array}{l}\text { Without DL and } \mathrm{NW}^{2} \\
(2)\end{array}$ & $\begin{array}{c}\text { Early consolidation }{ }^{2} \\
\text { (3) }\end{array}$ & $\begin{array}{c}\text { AA/CO placebo }{ }^{1} \\
(4)\end{array}$ & $\begin{array}{c}\text { DL/UA placebo }{ }^{2} \\
(5)\end{array}$ \\
\hline Constant & $\begin{array}{c}-3.780^{* * *} \\
(0.879)\end{array}$ & $\begin{array}{c}-4.435^{* * *} \\
(0.502)\end{array}$ & $\begin{array}{c}-3.301^{* * *} \\
(0.212)\end{array}$ & $\begin{array}{l}-2.365 \\
(1.499)\end{array}$ & $\begin{array}{c}-8.231^{* * *} \\
(1.035)\end{array}$ \\
\hline PFuel (log) & $\begin{array}{c}-1.200^{* * *} \\
(0.457)\end{array}$ & $\begin{array}{c}-2.506^{* * *} \\
(0.161)\end{array}$ & $\begin{array}{c}-2.646^{* * *} \\
(0.105)\end{array}$ & $\begin{array}{l}-0.242 \\
(0.691)\end{array}$ & $\begin{array}{l}-1.664 \\
(1.696)\end{array}$ \\
\hline Wage (log) & $\begin{array}{c}1.944^{* * *} \\
(0.564)\end{array}$ & $\begin{array}{c}2.793^{* * *} \\
(0.310)\end{array}$ & $\begin{array}{c}2.421^{* * *} \\
(0.128)\end{array}$ & $\begin{array}{c}0.946 \\
(0.831)\end{array}$ & $\begin{array}{c}5.032^{* * *} \\
(0.667)\end{array}$ \\
\hline Post & $\begin{array}{l}0.636^{*} \\
(0.352)\end{array}$ & $\begin{array}{c}1.603^{* * *} \\
(0.127)\end{array}$ & $\begin{array}{c}1.732^{* * *} \\
(0.083)\end{array}$ & $\begin{array}{c}0.004 \\
(0.382)\end{array}$ & $\begin{array}{c}0.991 \\
(1.292)\end{array}$ \\
\hline Post $\mathrm{x}$ Treated & $\begin{array}{l}-0.123 \\
(0.115)\end{array}$ & $\begin{array}{c}-0.308^{* * *} \\
(0.048)\end{array}$ & $\begin{array}{c}-0.277^{* * *} \\
(0.043)\end{array}$ & $\begin{array}{l}-0.163 \\
(0.122)\end{array}$ & $\begin{array}{l}-0.574 \\
(0.354)\end{array}$ \\
\hline Route fixed effect & Yes & Yes & Yes & Yes & Yes \\
\hline Carrier fixed effect & Yes & Yes & Yes & Yes & Yes \\
\hline Notes: & $\begin{array}{l}\text { Standard errors ar } \\
* * * \text { (resp., }{ }^{* *} \text { and }{ }^{*} \\
\text { 1. Pre-merger: } 200 \\
\text { 2. Pre-merger: } 200\end{array}$ & $\begin{array}{l}\text { clustered at the route } \\
\text { Significant at the } 1 \text { (res } \\
\text { 4:Q4-2007:Q4; Post-mer } \\
\text { 3:Q1-2007:Q4; Post-mer }\end{array}$ & $\begin{array}{l}\text { vel. } \\
\text {., } 5 \text { and 10) percent le } \\
\text { er: 2012:Q1-2015:Q1. } \\
\text { er: 2010:Q2-2015:Q1. }\end{array}$ & & \\
\hline
\end{tabular}

\footnotetext{
${ }^{11}$ The first placebo merger involves a fictitious merging firm (AA instead of UA) while the second one has a fictitious merged firm (UA instead of NW). One needs therefore to adopt different modelling strategies for these two placebo mergers. In the first case the merged carrier (CO) no longer tickets flights in the post merger period. Actually most of these flights are certainly ticketed by UA. We cannot consider that UA in these routes is unaffected by a $\mathrm{AA} / \mathrm{CO}$ merger. We therefore remove from the treatment group associated with placebo AA/CO placebo merger all the 734 routes actually treated in the UA/CO merger. It remains 1594 routes in the control group and 922 in the treatment group before applying the matching procedure, and 448 routes in the control group and 922 treated routes after applying this procedure. Note that the results reported in column (2) of Table 4 suppose no extensive margin, as in Table 2. In the case of the placebo merger between DL and UA, there is a fictitious merged carrier: UA indeed tickets flights following the fictitious merger. We impute all these tickets to DL (which removes UA from the post-merger sample). As in the previous placebo merger the 2,353 actually treated routes of the DL/NW must be removed since DL production already comprises part of NW production in these routes. We are left with few routes: 26 routes in the control group, and 1109 treated routes. The matching procedure selects 14 routes in the control group and 304 treated routes. Focusing on the intensive margin the final matched sample has 1618 observations. The results reported in column (5) of Table 4 obtain from this sample.
} 


\section{E.2 Pre and post-merger period definition}

To account for the possible coordination in advance of the actual merger, we run two exercises where the DL/NW pre-merger period is 2002:Q1-2006:Q4 and 2001:Q1-2005:Q4, respectively. In both cases the post-merger period is set as in Table 2 to the completion period (2010:Q2-2015:Q1). In both cases we find a significant stabilizing impact of the merger, with Post $\times$ Treated coefficient equal to -0.308 and -0.176 (and p-values less than 0.01).

We also study the robustness of our results to a change in the sample window. Figure 2 depicts how the estimated impact of the DL/NW merger changes over time. We always set a pre-merger period ending in 2007:Q4 and a post-merger period starting in 2008:Q2. The figure gives the Post $\times$ Treated coefficient (in red) as well as its 5 percent confidence interval (in blue) for our most general specification (including cost controls and route and carrier fixed effects) when the end of the post-merger period varies from 2009:Q1 to 2015:Q1. In the main text we controlled for seasonality and possible trend of the number of passengers transported by choosing pre and post-merger periods containing the same number of each quarter. In Figure 2 the pre-merger period and the post-merger period have the same length, proceeding backward from the quarter preceding announcement (2007:Q4). For instance, the 10 quarter post-merger period starting in 2008:Q2 and ending in 2010:Q3 is associated with the 10 quarter pre-merger period starting in 2005:Q3 and ending in 2007:Q4. In general the number of each quarter contained in the two periods differ. Figure 2 however shows that the result reported the column (2) of Table 3 are robust to this weaker control for seasonality. Except for the completion quarter 2010:Q1 the DL/NW merger has implied a steady increase in volatility until the end of 2010, reaching it maximum in 2010:Q4. Volatility then dampens and the gain in stability occurs about two years after the completion. The $15 \%$ reduction in the coefficient of variation of the number of passengers reported in Table 3 is obtained in 2013 and remains about unchanged from this date. ${ }^{12}$

\section{E.3 Stabilization impact for other mergers}

Finally we have applied the same methodology to three other recent mergers: the merger between United Airlines (UA) and Continental Airlines (CO), announced in 2008:Q1 and completed in 2011:Q4; the one between US Airways (US) and America West (HP), officially announced in 2005:Q2 and completed in 2007:Q2; and the recent merger between Southwest Airlines (WN) and AirTran Airways (FL), announced in 2010:Q4 and completed in 2014:Q4. In each case we have followed the same methodology as the one used for the DL/NW merger for choosing pre and post-merger periods and for selecting the matched treated and control

\footnotetext{
${ }^{12}$ Part of this evolution is certainly driven by the progressive increase in the number of points which enter in the computation of the standard error of the number of passengers, an additional quarter loosing importance as the width of the time window is enlarged.
} 


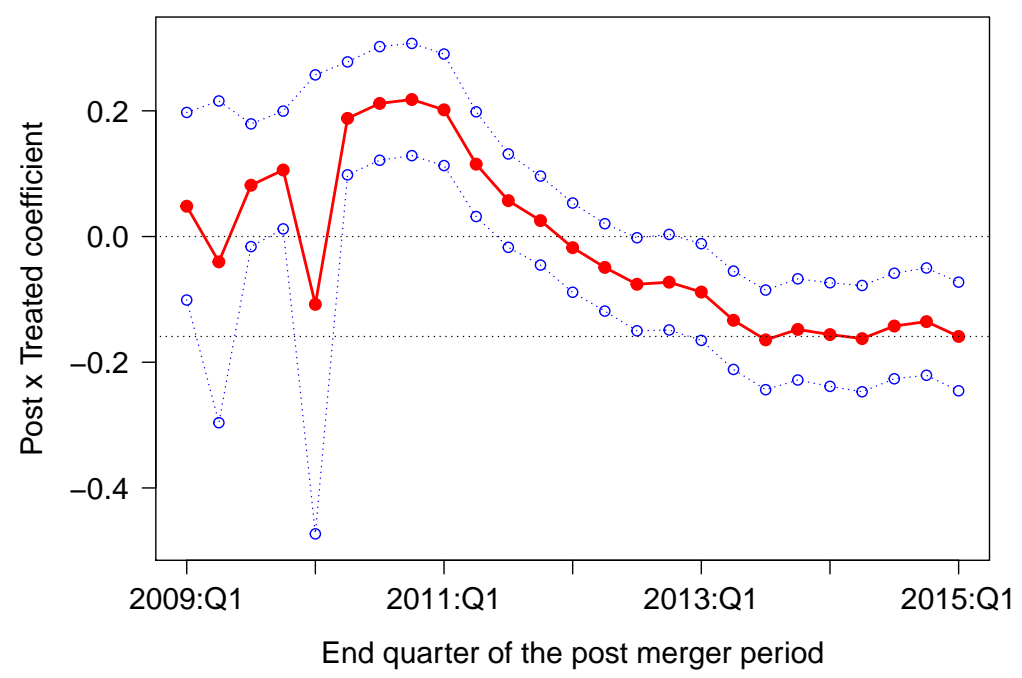

Figure 2: Change in volatility over time

routes. ${ }^{13}$ The results are consistent with those reported in the main text for the DL/NW merger. The first two mergers yield less volatility in the number of passengers. Volatility is unaffected by the third merger, where the post-merger period only covers the quarters from announcement to completion.

\footnotetext{
${ }^{13}$ In the case of the US/HP 42 treated routes satisfy presence requirements in the market before the matching procedure, but only 1 route remains at the outcome of the matching. The results reported in column (2) of Table 5 are obtained from the full sample, i.e., without applying route matching.
} 
Table 5: Results for other mergers

\begin{tabular}{|c|c|c|c|}
\hline & $\begin{array}{c}\mathrm{UA}^{\mathrm{A}} \mathrm{CO}^{1} \\
(1)\end{array}$ & $\begin{array}{c}\mathrm{US} / \mathrm{HP}^{2} \\
(2)\end{array}$ & $\begin{array}{c}\mathrm{WN} / \mathrm{FL}^{3} \\
(3)\end{array}$ \\
\hline Constant & $\begin{array}{c}-3.672^{* * *} \\
(0.831)\end{array}$ & $\begin{array}{c}1.127^{* * *} \\
(0.320)\end{array}$ & $\begin{array}{c}-9.252^{* * *} \\
(0.634)\end{array}$ \\
\hline PFuel (log) & $\begin{array}{c}0.055 \\
(0.241)\end{array}$ & $\begin{array}{c}0.018 \\
(0.378)\end{array}$ & $\begin{array}{c}4.004^{* * *} \\
(0.455)\end{array}$ \\
\hline Wage (log) & $\begin{array}{c}1.807^{* * *} \\
(0.456)\end{array}$ & $\begin{array}{c}-1.262^{* * *} \\
(0.180)\end{array}$ & $\begin{array}{c}2.848^{* * *} \\
(0.283)\end{array}$ \\
\hline Post & $\begin{array}{c}0.038 \\
(0.279)\end{array}$ & $\begin{array}{c}0.268 \\
(0.414)\end{array}$ & $\begin{array}{c}-1.021^{* * *} \\
(0.122)\end{array}$ \\
\hline Post $\times$ Treated & $\begin{array}{c}-0.364^{* *} \\
(0.175)\end{array}$ & $\begin{array}{c}-0.214^{* * *} \\
(0.055)\end{array}$ & $\begin{array}{c}0.021 \\
(0.060)\end{array}$ \\
\hline $\begin{array}{l}\text { Route fixed effect } \\
\text { Carrier fixed effect } \\
\text { Nb of observations }\end{array}$ & $\begin{array}{c}\text { Yes } \\
\text { Yes } \\
8,473 \\
\end{array}$ & $\begin{array}{c}\text { Yes } \\
\text { Yes } \\
15,412 \\
\end{array}$ & $\begin{array}{c}\text { Yes } \\
\text { Yes } \\
1,639 \\
\end{array}$ \\
\hline Notes: & $\begin{array}{l}\text { Standard e } \\
\text { *** (resp., } \\
\text { 1. Matched } \\
\text { Pre-merg } \\
\text { 2. Full inte } \\
\text { Pre-merg } \\
\text { 3. Matched } \\
\text { Pre-merg }\end{array}$ & $\begin{array}{l}\text { ors are clus } \\
\left.\text { and }{ }^{*}\right) \text { Sig } \\
\text { ntensive sa } \\
\text { r: 2004:Q3: } \\
\text { sive sample } \\
\text { : 2001:Q2- } \\
\text { ntensive sa } \\
\text { : } 2006: Q 4-\end{array}$ & $\begin{array}{l}\text { evel. } \\
\text { sp., } 5 \text { and 10) percent level. } \\
\text { er: 2012:Q1-2015/01. } \\
\text { ger: 2008:Q2-2012:Q1. } \\
\text { ger: 2011:Q1-2014:Q4. }\end{array}$ \\
\hline
\end{tabular}




\section{$\mathrm{R}$ code leading to Table 2 - not to be published -}

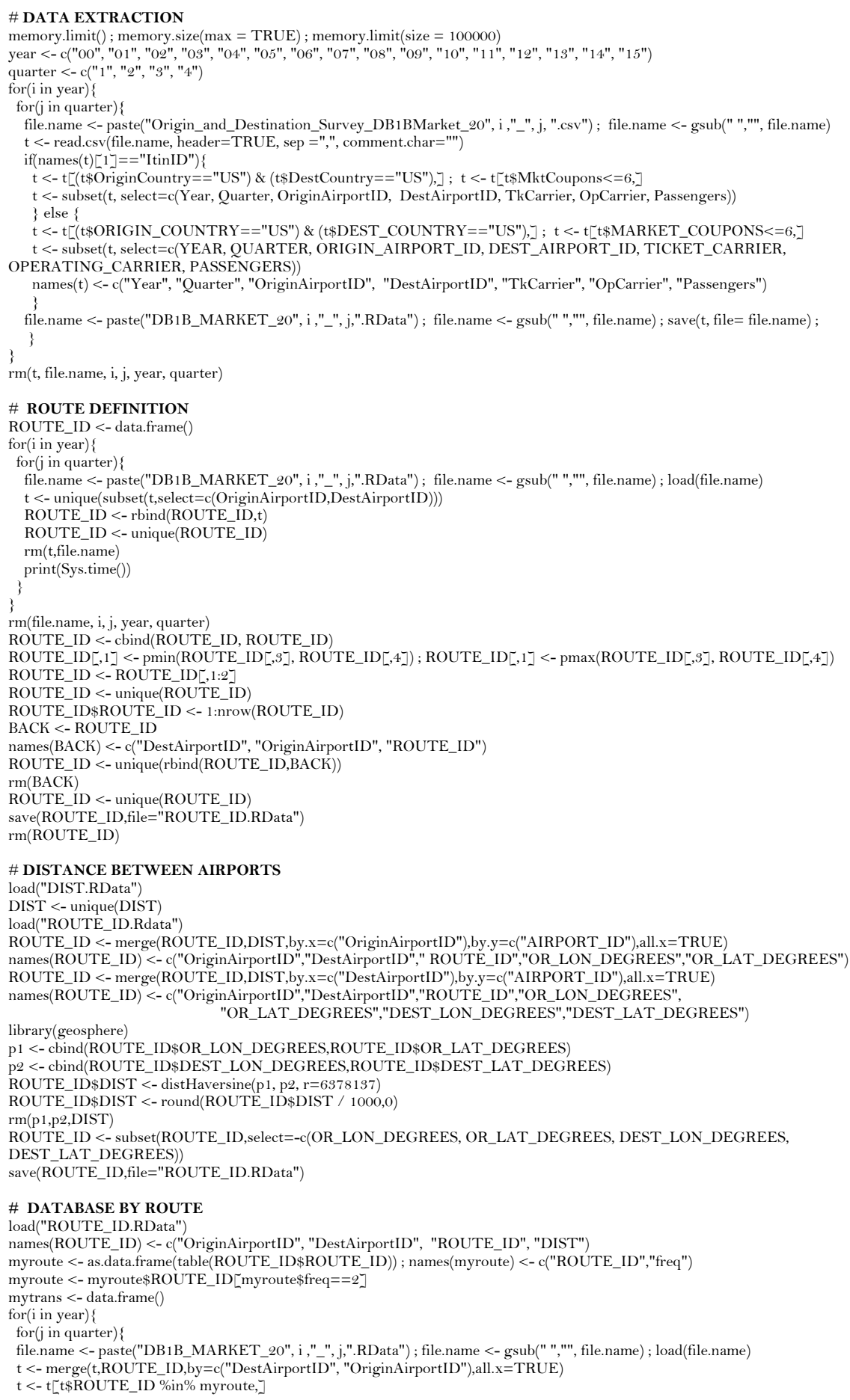




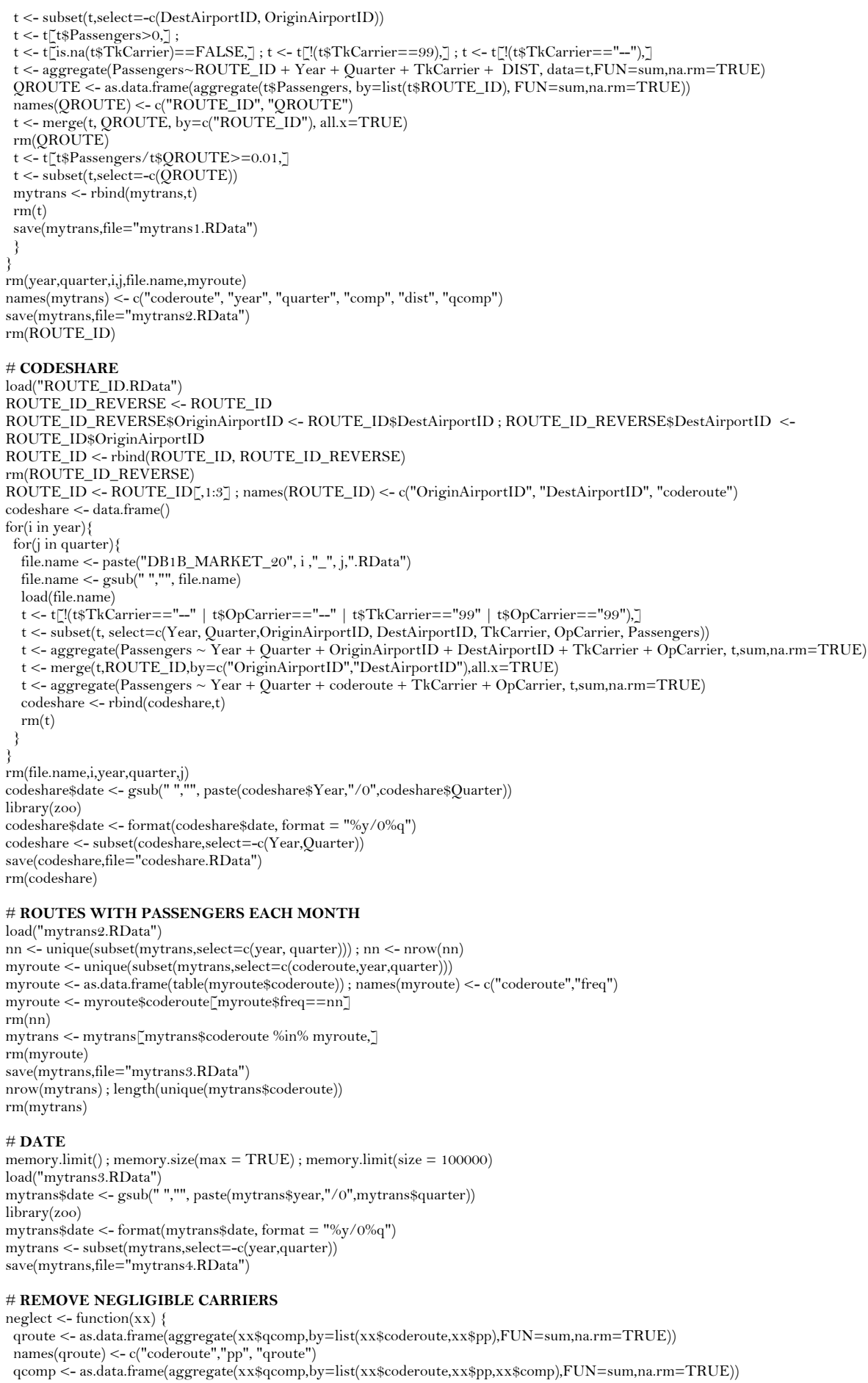




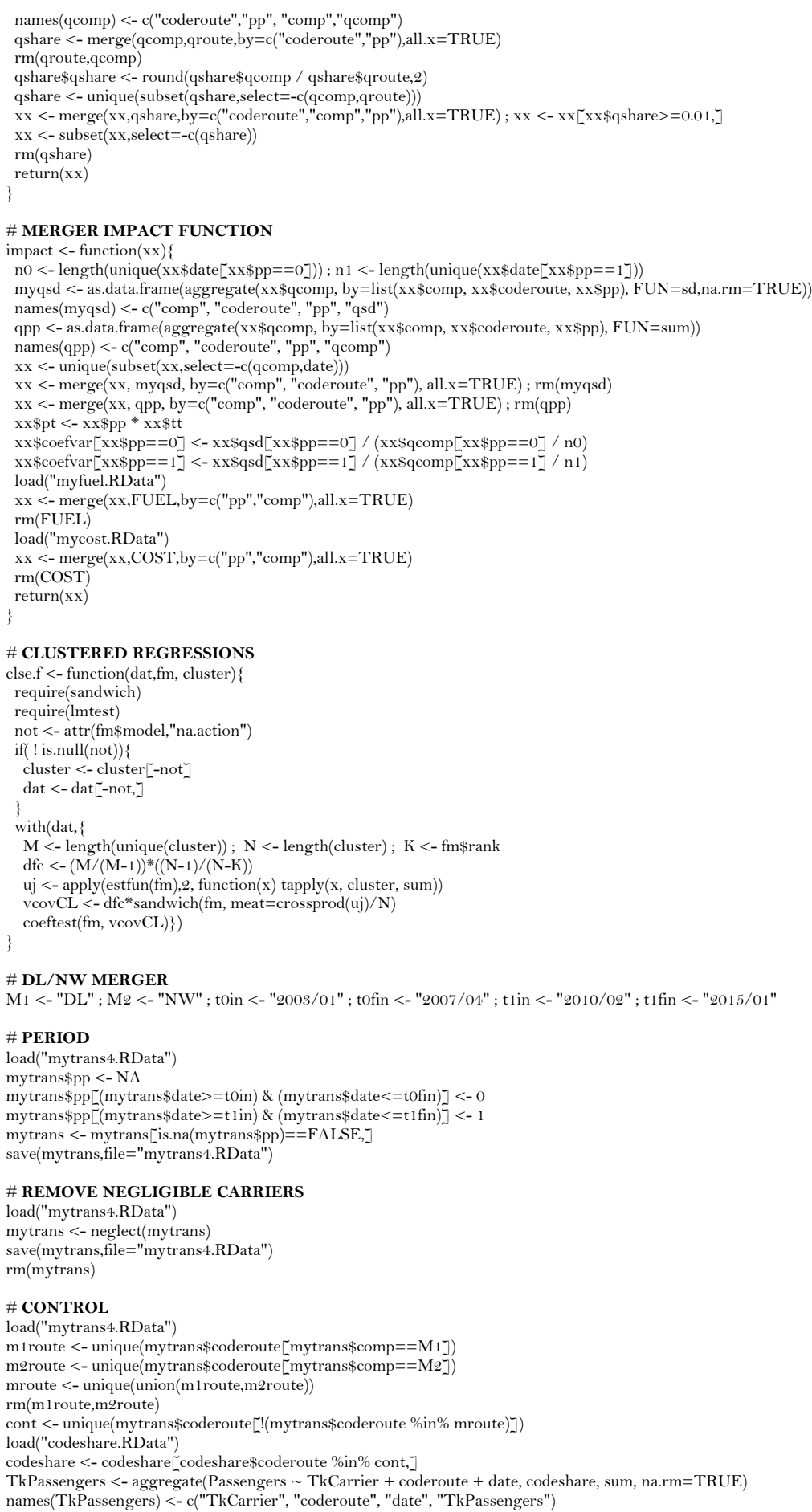




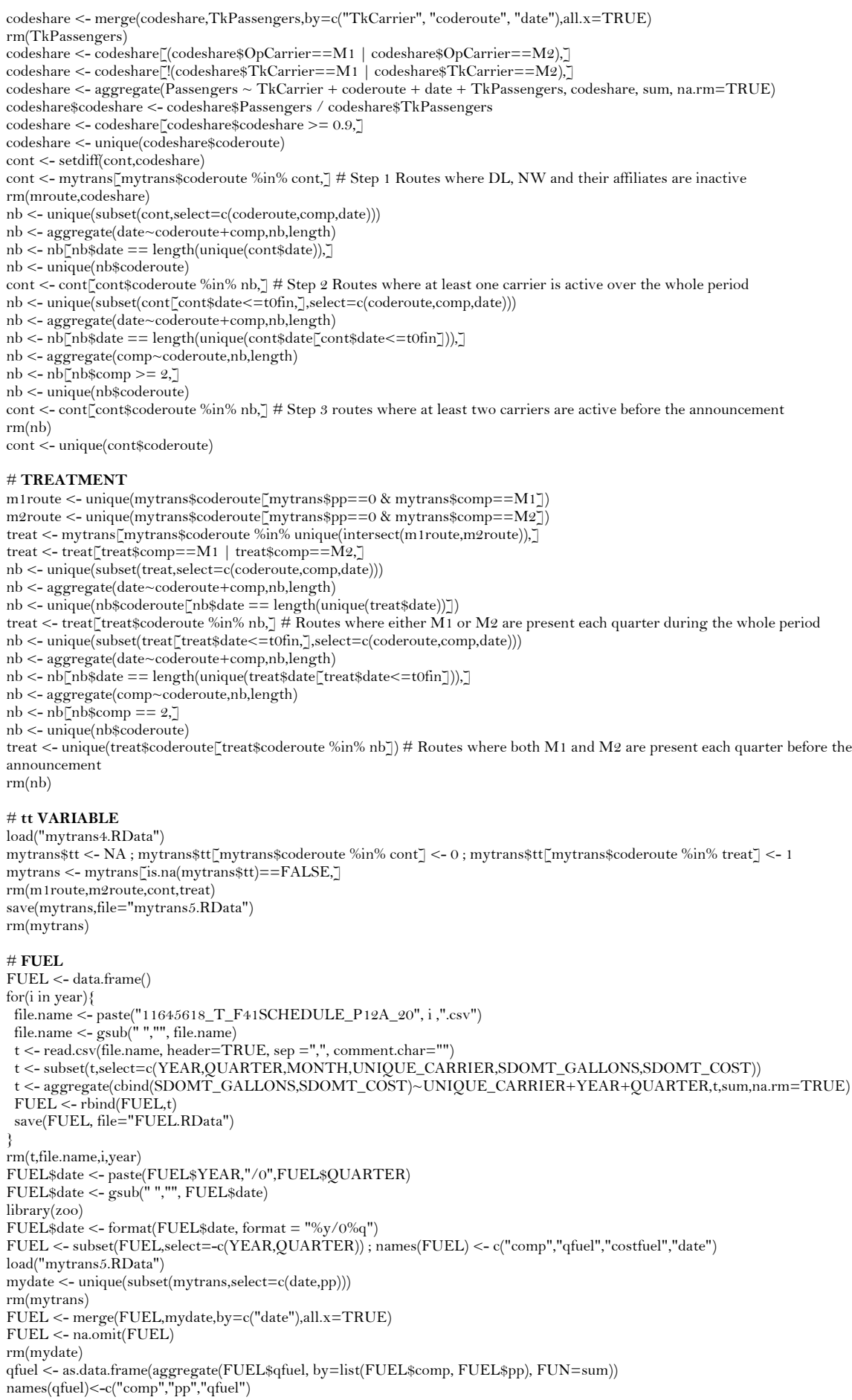




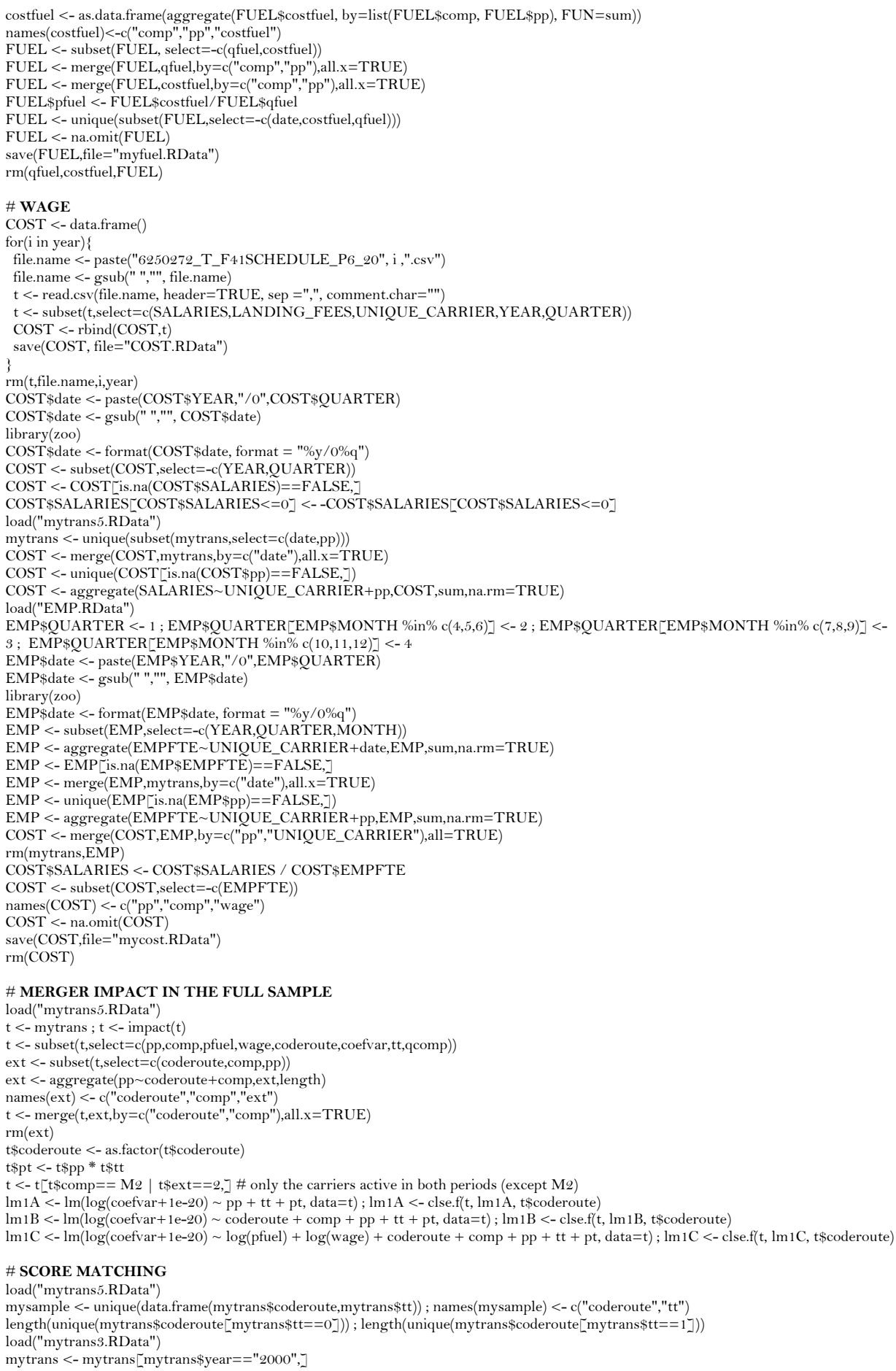




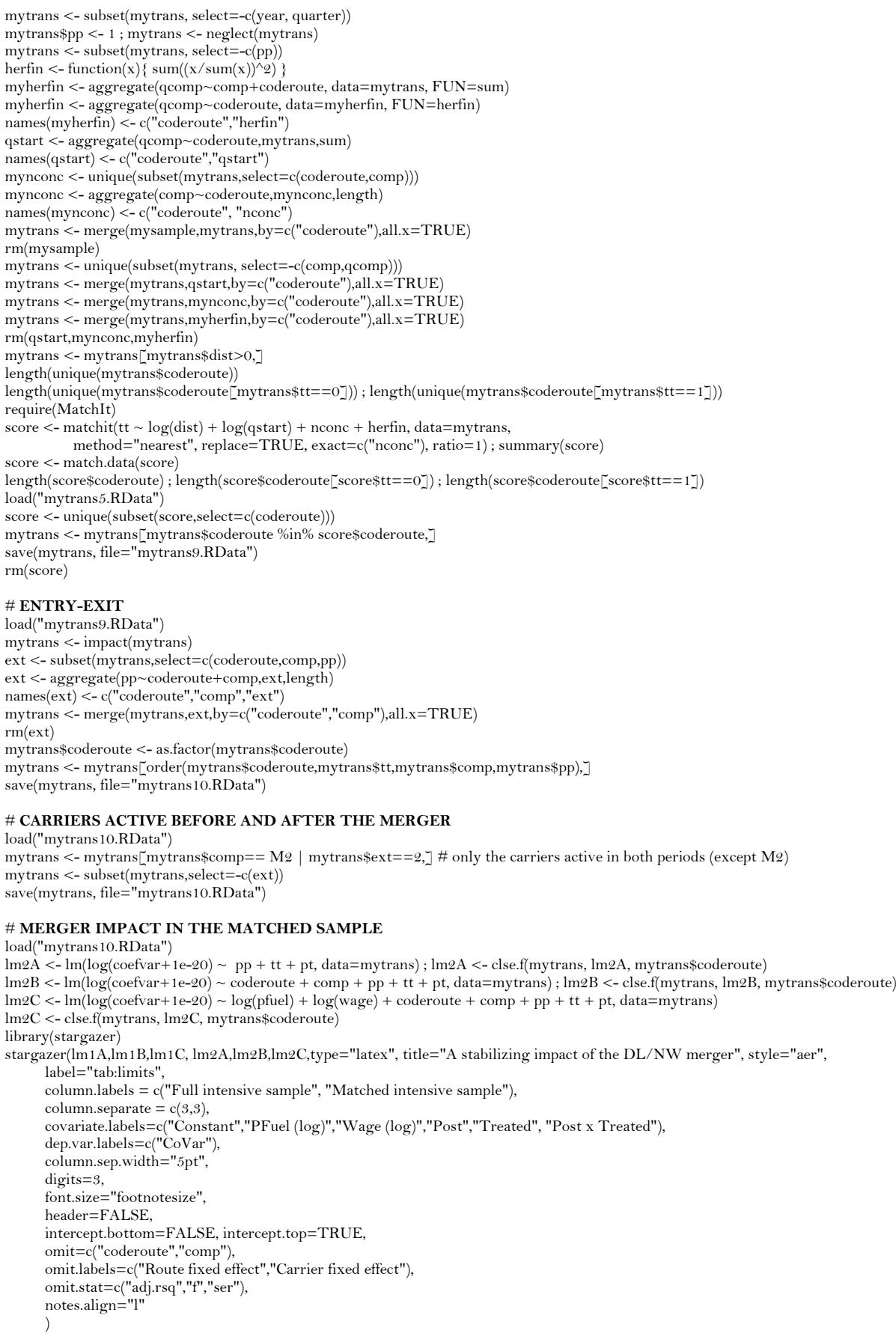

\section{\# MERGER IMPACT IN THE MATCHED SAMPLE}

load("mytrans 10.RData")

$\operatorname{lm} 2 \mathrm{~A}<-\operatorname{lm}(\log ($ coefvar+le-20 $) \sim \mathrm{pp}+\mathrm{tt}+\mathrm{pt}$, data=mytrans $) ; \operatorname{lm} 2 \mathrm{~A}<-$ clse $\mathrm{f}($ mytrans, $\operatorname{lm} 2 \mathrm{~A}$, mytrans $\$$ coderoute $)$

$\operatorname{lm} 2 \mathrm{~B}<-\operatorname{lm}(\log ($ coefvar $+1 \mathrm{e}-2 \mathrm{O}) \sim$ coderoute + comp $+\mathrm{pp}+\mathrm{tt}+\mathrm{pt}$, data=mytrans $) ; \operatorname{lm} 2 \mathrm{~B}<-$ clse.f(mytrans, $\operatorname{lm} 2 \mathrm{~B}$, mytrans $\$$ coderoute $)$

$\operatorname{lm} 2 \mathrm{C}<-\operatorname{lm}(\log ($ coefvar $+1 \mathrm{e}-2 \mathrm{O}) \sim \log ($ pfuel $)+\log ($ wage $)+$ coderoute + comp $+\mathrm{pp}+\mathrm{tt}+\mathrm{pt}$, data=mytrans $)$

$\operatorname{lm} 2 \mathrm{C}<-$ clse.f(mytrans, $\operatorname{lm} 2 \mathrm{C}$, mytrans $\$$ coderoute)

library(stargazer)

stargazer $(\operatorname{lm} 1 \mathrm{~A}, \operatorname{lm} 1 \mathrm{~B}, \operatorname{lm} 1 \mathrm{C}, \operatorname{lm} 2 \mathrm{~A}, \operatorname{lm} 2 \mathrm{~B}, \operatorname{lm} 2 \mathrm{C}$,type="latex", title="A stabilizing impact of the DL/NW merger", style="aer",

label="tab:limits",

column.labels = $\mathrm{c}($ "Full intensive sample", "Matched intensive sample"),

column.separate $=\mathrm{c}(3,3)$,

covariate.labels=c("Constant","PFuel $(\log )$ ),"Wage $(\log )$ ","Post","Treated", "Post x Treated"),

dep.var.labels $=c(" C o V a r ")$,

column.sep.width="5pt",

digits $=3$,

font.size $=$ "footnotesize",

header $=$ FALSE,

intercept.bottom $=$ FALSE, intercept.top $=$ TRUE,

omit=c("coderoute","comp"),

omit.labels=c("Route fixed effect","Carrier fixed effect")

omit.stat=c("adj.rsq","f","ser"),

notes.align="l"

) 